\title{
Bundling Time and Goods: Implications for Hours Dispersion
}

\author{
Lei Fang, Anne Hannusch, and Pedro Silos
}

\author{
Working Paper 2020-1 \\ January 2020
}

\begin{abstract}
We document the large dispersion in hours worked in the cross-section. We account for this fact using a model in which households combine market inputs and time to produce a set of nonmarket activities. To estimate the model, we create a novel data set that pairs market expenditures and time use at the activity level using data from the Consumer Expenditure Survey and the American Time Use Survey, respectively. The estimated model can account for a large fraction of the dispersion of hours worked in the data. The substitutability between market inputs and time within an activity and across a sizable number of activities is key to our results. We show that models that lack these features can only generate one third of the observed hours dispersion.
\end{abstract}

JEL classification: J22, E21, D11

Key words: time allocation, consumption expenditures, hours dispersion, elasticity of substitution

https://doi.org/10.29338/wp2020-01

The authors thank audiences at various conferences and universities for useful comments. They want to especially thank Yongsung Chang, Nicola Fuchs-Schündeln, Nezih Guner, Karen Kopecky, Dirk Krueger, Rachel Ngai, B. Ravikumar, Richard Rogerson, Chris Tonetti, and Gianluca Violante for feedback at all stages of this project. The views expressed here are those of the authors and not necessarily those of the Federal Reserve Bank of Atlanta or the Federal Reserve System. Any remaining errors are the authors' responsibility. Hannusch gratefully acknowledges financial support by the German Research Foundation (DFG) through CRC TR 224 (project A03).

Please address questions regarding content to Lei Fang, Research Department, Federal Reserve Bank of Atlanta, 1000 Peachtree Street NE, Atlanta, GA 30309-4470, 404-498-8057, lei.fang@atl.frb.org; Anne Hannusch, Department of Economics, University of Mannheim, L7, 3-5 Room P.03, Mannheim, Germany 68161, hannusch@uni-mannheim.de; or Pedro Silos, Department of Economics, Temple University, Ritter Annex 879, 1301 Cecil B. Moore Ave., Philadelphia, PA 19122, pedrosilos@gmail.com.

Federal Reserve Bank of Atlanta working papers, including revised versions, are available on the Atlanta Fed's website at www.frbatlanta.org. Click "Publications" and then "Working Papers." To receive e-mail notifications about new papers, use frbatlanta.org/forms/subscribe. 


\section{Introduction}

The dispersion of market hours across workers is large. The literature thus far has relied on unobserved tastes for leisure to generate the hours dispersion that we observe in the data. ${ }^{1}$ Explaining hours dispersion instead as a result of observables improves our understanding of the earnings distribution, which is an essential ingredient in analyzing questions in macroeconomics, labor economics, and public finance.

This paper proposes a model that generates large dispersion in hours worked in the absence of preference heterogeneity and is consistent with the rich crosssectional patterns of time use and expenditures. In the model, households combine time and market inputs (goods and services) to enjoy non-market activities. Throughout the paper, we define non-market activities as activities related to home production and leisure. One example of such an activity is a restaurant meal. It requires the purchase of market goods and services, combined with a person's own time to enjoy utility from restaurant meals; such utility cannot be enjoyed without both inputs. This idea goes back to Becker (1965), and while it forms the basis of the home production literature, we generalize the idea to include all non-market activities households engage in. Our innovation is to divide non-market hours into time segments, in which each segment is paired with specific market inputs to produce an activity.

The observed heterogeneity we rely on to explain hours dispersion is the heterogeneity in wages. In our model, the response of hours worked to wage changes depends on the substitutability between market inputs and time within an activity and across activities. Hence, to what extent wage dispersion translates into hours dispersion depends on the magnitude of these two types of elasticities of substitution and, ultimately, remains a quantitative question.

Estimating the model inspired by Becker (1965) is challenging, as it requires data on time use and market inputs bundled at the activity level. Our first contribution is to create a novel data set that maps time-use categories from the Amer-

\footnotetext{
${ }^{1}$ See, for example, Kaplan (2012) or Heathcote et al. (2014).
} 
ican Time Use Survey (ATUS) and market input categories from the Consumer Expenditure Survey (CEX) into a common set of activities. Our reference is the set of activities proposed by Aguiar et al. (2013), who classify time-use data into market work, child care, non-market work (home production), and several leisure categories. We take these categories as given and map market input expenditures into these time-use categories. By averaging time and expenditures for households belonging to the same educational group in a given year, we construct a pseudopanel of household allocations over the sample period 2003-2014.

From this newly created data set, we document substantial heterogeneity in the time and expenditure bundles allocated to different activities. Market work requires hardly any expenditures and varies mostly along the time dimension. Highly educated households spend significantly more time working in the market. Non-market work activities, on the other hand, are mostly heterogeneous in terms of the expenditures allocated to them. Less educated households spend a much larger fraction of their budget on these activities. Finally, leisure activities stand out. They exhibit heterogeneity along both dimensions of time and expenditure. Highly educated households allocate less time to leisure, but they spend a larger fraction of their budget on these activities. Despite overall lower leisure hours, more educated households devote more time to leisure activities that require more expenditures, such as dining out and vacations. Less educated households, in contrast, spend more time on leisure activities that require lower expenditures, such as watching TV.

We supplement the pseudo-panel of time and expenditure bundles with data on wages and prices to estimate the model. The form of preferences we take to the data is of the nested constant elasticity of substitution (CES) type. The utility from each activity is a CES aggregator of market inputs and time. We estimate the elasticities of substitution between market inputs and time for a set of six nonmarket activities, as well as the elasticity of substitution across these activities. We find that one can substitute market inputs with time quite easily for a given activity and that activities themselves are substitutable, but to a lesser extent.

We simulate the model and show that it accounts for $55 \%$ of the dispersion 
in market hours over the sample period. The only source of heterogeneity in the model stems from the cross-sectional distribution of wages, which we take from the Current Population Survey. Two model innovations account for this result: (1) the division of non-market time into activity-specific segments and (2) the inclusion of a sizable number of non-market activities. The estimation suggests a high degree of substitutability between market inputs and time within most activities as well as across activities. This empirical finding, in combination with the two model innovations, implies that time allocation choices are much more sensitive to wage changes: Households not only reallocate market inputs and non-market time within a given activity but also across a large set of activities. These additional margins of adjustment imply large responses of market hours to changes in wages.

We estimate several alternative utility specifications using the same data to explore the importance of the two model innovations. To disentangle the importance of the first innovation, we estimate a form of CES utility that includes the same number of market inputs but lumps all non-market time together in the standard notion of leisure. This model can only account for $29 \%$ of the dispersion in hours worked. To capture the importance of the second innovation, we estimate the same model but reduce the number of activities from six to two. This model can only account for $32 \%$ of the dispersion in hours worked.

Related Literature This paper contributes to a large and growing literature on home production and leisure production. ${ }^{2}$ More specifically, it generalizes the idea of home or leisure production and fully exploits the heterogeneity in the household production of consumption activities outside the market. We argue that such a generalization is crucial to understanding the cross-sectional dispersion in hours worked.

This paper also relates to the literature on time allocation. The most prominent example is Aguiar and Hurst (2007b), who document trends in time allocated to market work, non-market work, and leisure. A more recent paper, Aguiar et al.

\footnotetext{
${ }^{2}$ See, for example, Benhabib et al. (1991), Greenwood and Hercowitz (1991), McGrattan et al. (1997), Vandenbroucke (2009), Kopecky (2011), Ngai and Pissarides (2011), Bridgman (2016), Fang and Zhu (2017), Ngai and Petrongolo (2017) and Bopphart and Ngai (2019).
} 
(2019), finds that innovations in recreational computing technology can account for a large fraction of the decline in young men's labor supply since 2004. We contribute to this literature by mapping time use categories to expenditure categories. This mapping allows us to study how bundles of time and market inputs differ across a wide set of non-market activities and household types. More recently, Boerma and Karabarbounis (2019a) and Boerma and Karabarbounis (2019b) study welfare inequality using an alternative approach to obtain time and expenditures for home and leisure production. They impute levels of time use for households in the CEX using variables that are common to the CEX and the ATUS. The mapping we propose does not rely on any imputation, and we present expenditures and time use for a much larger set of activities.

Finally, this paper relates to the macroeconomic literature that studies inequality (e.g. Heathcote et al. (2014) and Kaplan (2012)), unemployment (Bils et al. (2012)), and the relationship between wealth and labor supply heterogeneity (Mustre del Rio (2015)). These papers rely on ex ante heterogeneity in preferences for leisure to generate dispersion in hours worked. The model presented in this paper, in contrast, does not rely on preference heterogeneity. It generates dispersion in hours only through heterogeneity in wages, which is observable and relatively well measured.

The rest of the paper is organized as follows. Section 2 presents data facts on the dispersion in hours worked and bundles of time use and market inputs across different activities. Section 3 presents the model. Section 4 discusses the estimation strategy and estimation results. Section 5 uses the estimated models to understand the effects of wage dispersion on hours dispersion. Section 6 concludes.

\section{Data}

We begin by documenting the large dispersion in hours worked within and across education groups. We argue that this dispersion may reflect heterogeneity in household choices outside the market. To this end, we provide evidence that bundles of market inputs and time for non-market activities vary by education level. 
We group households into four education categories: (1) less than high school, (2) high school, (3) some college, and (4) college and above.

\subsection{Dispersion of Hours Worked}

We measure dispersion of hours worked as the standard deviation of log usual hours worked in the Current Population Survey Outgoing Rotation Group (CPSORG) between 2003 and 2014. We restrict the sample to individuals between the ages of 21 and 65. Table 1 summarizes the results across all years and for two subperiods: 2003-2007 and 2008-2014. Dispersion in hours worked is slightly higher for more educated individuals and increased somewhat during and after the Great Recession. However, the variation across education groups and across time periods is relatively small. Hence, we use the average dispersion over the entire sample period as the benchmark for our analysis.

Table 1: Dispersion in Hours Worked

\begin{tabular}{lccc}
\hline & $2003-2014$ & $2003-2007$ & $2008-2014$ \\
\hline Less than HS & 0.402 & 0.380 & 0.419 \\
High School & 0.397 & 0.385 & 0.405 \\
Some College & 0.445 & 0.439 & 0.449 \\
College & 0.464 & 0.469 & 0.460 \\
\hline Total & 0.435 & 0.428 & 0.440 \\
\hline
\end{tabular}

Data Source: IPUMS-CPS Outgoing Rotation Group 2003-2014. The sample is restricted to workers aged 21-65. Dispersion of hours worked is measured as the standard deviation of log usual hours worked per week. If usual hours worked per week is not available, we use information on actual hours worked.

\subsection{Time and Expenditure Allocations}

\subsubsection{Data Construction}

To the best of our knowledge, no single data source includes bundles of expenditures and time use for a broad set of activities. Hence, we use the Consumer Expenditure Survey (CEX) for data on market inputs and combine it with time use data from the American Time Use Survey (ATUS) at the activity level. We restrict both samples to reference persons between the ages of 21 and 65. We remove students and retirees, since we do not model education or retirement decisions. Be- 
cause our main focus is the dispersion of market hours, we also restrict the sample to households with working individuals. The sample period is 2003-2014.

Our first contribution is to develop a mapping that consistently links market input expenditures to time use at the activity level. We take the time use classification of Aguiar and Hurst (2007b), Aguiar et al. (2012) and Aguiar et al. (2019) as our starting point. Matching expenditures to these time use categories involves two steps. First, we create a baseline match between both surveys using the aggregated consumption expenditure categories provided by the Bureau of Labor Statistics. We then check the detailed expenditure series underlying these major categories. If necessary, we reassign expenditure subseries to different time use categories in order to maintain a consistent mapping. The details of the data construction process are described in Appendix A.

Some expenditures cannot be directly linked to a specific activity; these mainly constitute investment decisions. For example, the purchase of a house or car is not only a consumption decision but also an investment decision. ${ }^{3}$ Similarly, expenditures spent on education and medical care are part of the investment in human capital. ${ }^{4}$ Given the static framework presented in this paper, we choose to exclude all investment expenditures from our main analysis. In addition, expenditures on transportation, such as gas, maintenance of a vehicle, public transportation, etc., cannot be separated into direct transportation costs associated with actual activities. We therefore also exclude these from our analysis. We refer to the set of expenditures included in our analysis as "core expenditures." Between 2003 and 2014, core expenditures constitute slightly more than half of total consumption expenditures reported in the CEX.

Our proposed mapping between time use and expenditures leads to four main activity categories: market work, non-market work, child care, and leisure, where non-market work is mostly home production. Leisure itself can be divided into five subcategories: watching TV, sleep, socializing, eating out and personal care, and hobbies and entertainment. Please refer to Tables A.1-A.4 for a detailed description

\footnotetext{
${ }^{3}$ The maintenance costs of a house are included in non-market work.

${ }^{4}$ For consistency, we also exclude time spent on education and medical care from the analysis.
} 
of these categories.

\subsubsection{Stylized Facts}

Figure 1 documents substantial heterogeneity by education in the time and expenditure bundles allocated to each of the four main activities. Time spent on each activity is reported in weekly hours and plotted on the $x$-axis. Expenditures for market inputs allocated to the same activity are shown on the $y$-axis and reported as a fraction of core expenditures. Households are grouped by educational attainment, with group 1 having the lowest attainment. We report average allocations over the entire sample period as time and expenditure shares vary little over time.

Figure 1: Main Activities by Education

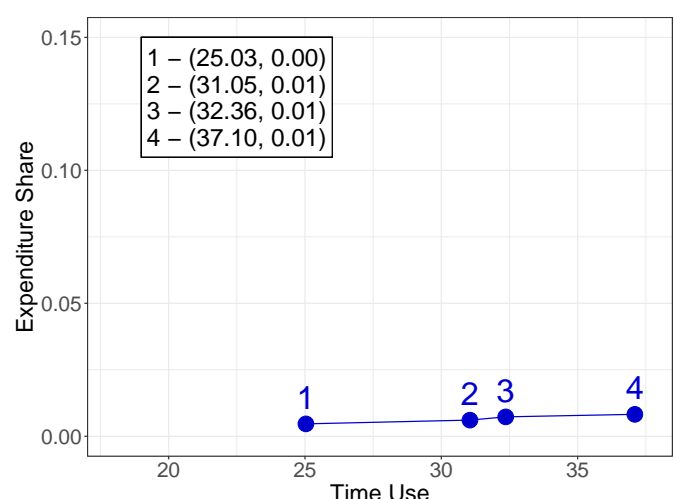

(a) Market Work

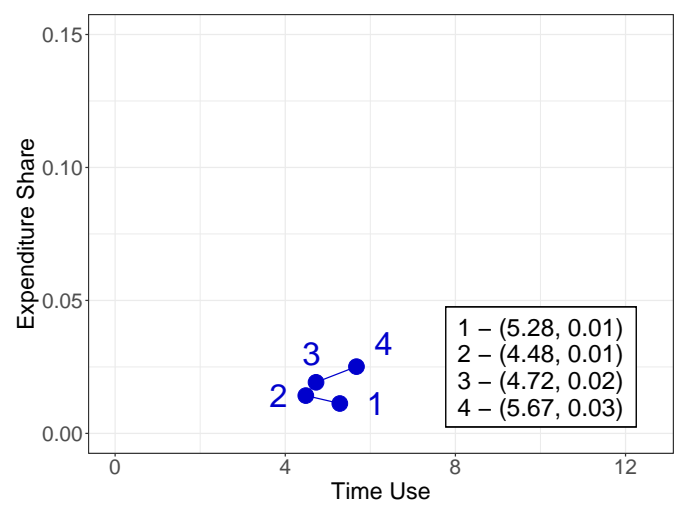

(c) Child Care

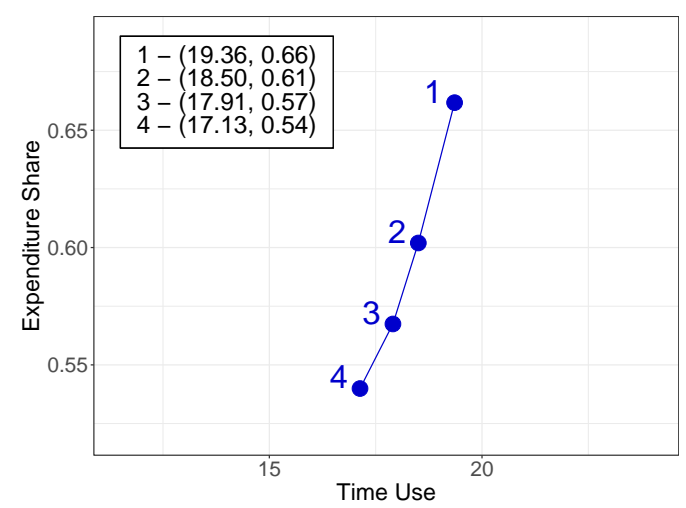

(b) Non-Market Work

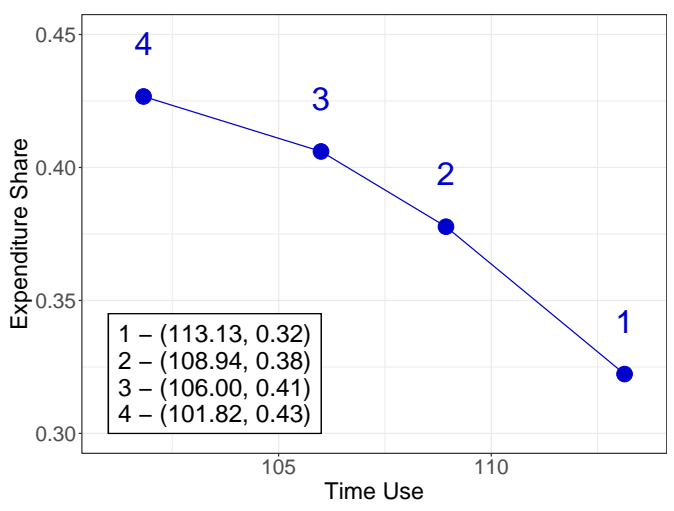

(d) Leisure

Notes: Households are grouped into four education groups: 1 - less than high school, 2 - high school, 3 - some college, 4 - college and above. Consumption expenditures are expressed as a fraction of core expenditures. Time use is reported as weekly hours.

First, market work requires hardly any expenditures at the household level, but varies tremendously in terms of time allocation. College-educated households 
Figure 2: Leisure Activities By Education

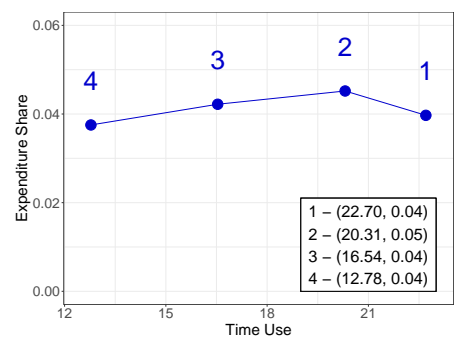

(a) Watching TV

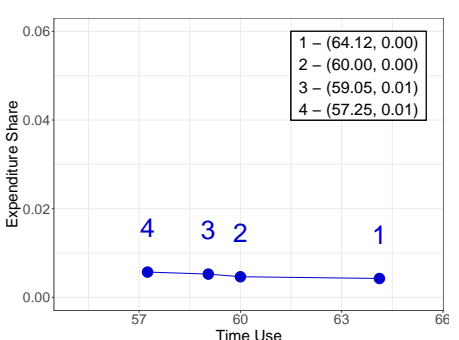

(b) Sleep

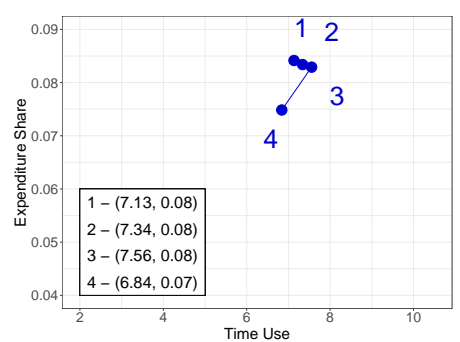

(c) Socializing

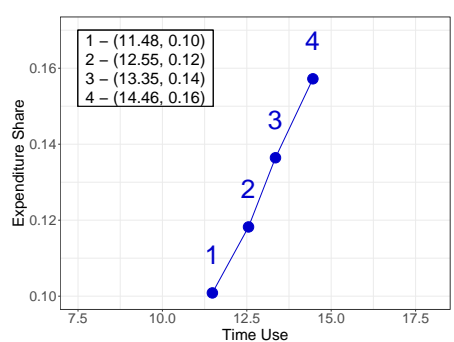

(d) Eating and Personal Care

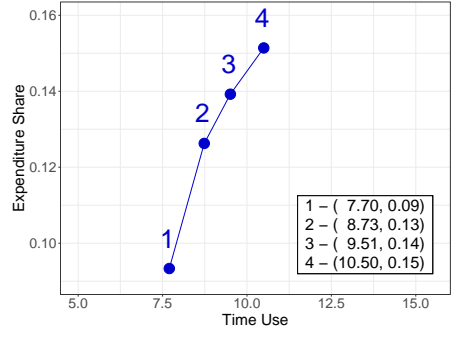

(e) Hobbies and Entertainment

Notes: Households are grouped into four education groups: 1 - less than high school, 2 - high school, 3 - some college, 4 - college and above. Consumption expenditures are expressed as a fraction of core expenditures. Time use is reported as weekly hours.

spend roughly 12 hours more per week working in the market compared to high school dropouts. The opposite is true for non-market work. Time allocated to nonmarket work varies little by education. Yet, non-market work activities constitute one-half to two-thirds of core expenditures. The expenditure share is declining in education, with high school dropouts allocating 12 percentage points more of their budget to non-market work activities relative to college graduates. Expenditures on child care are increasing in education, while weekly hours spent on child care are U-shaped.

The time and expenditure bundles for leisure activities follow a strikingly different pattern. These bundles vary along both dimensions with educational attainment. Expenditure shares for leisure activities are increasing in education, while time use is decreasing. For example, high school dropouts enjoy 11 more leisure hours per week than college graduates, which roughly mirrors the difference in market hours. Meanwhile, high school dropouts spend 11 percentage points less of their expenditures on leisure activities.

To understand what drives the pattern of time and expenditure bundles for 
leisure, we decompose leisure activities into five subcategories. Figure 2 plots time use and expenditure shares for these subcategories. Sleep and watching TV are the two leisure activities that absorb the majority of leisure time. The difference in leisure hours by education is mainly driven by these two activities. High school dropouts spend 10 hours more per week watching TV and 7 hours more sleeping than college graduates. Both activities are associated with hardly any expenditures.

Hobbies and entertainment and eating out and personal care, are the two leisure activities that dominate household expenditures. These activities drive the increase in leisure expenditure shares by education. College graduates spend 12 percentage points more of their core expenditures on both categories compared with high school dropouts. Although college graduates overall spend less time on leisure, they allocate 6 hours more per week between hobbies and entertainment and eating out and personal care. Taken together, these facts rationalize why more educated households spend less time but a larger fraction of their budget on leisure activities.

We perform several checks to demonstrate the robustness of these stylized facts. First, we split the 2003-2014 sample into two subperiods, 2003-2007 and 2008-2014. The cross-sectional time and expenditure allocations look similar for the two subsamples. ${ }^{5}$ Next, instead of grouping households by education, we split them by income quartiles. Figures B.1 and B.2 in the Appendix show the results when we split households along income quartiles. Even though all results go through, we lose a nontrivial number of observations due to the fact that the household income variable in the ATUS contains a lot of missing observations. Hence, we choose to continue the analysis with the education classification.

\section{Structural Framework}

\subsection{The Model}

Becker (1965) emphasizes that different types of time use and different types of

\footnotetext{
${ }^{5}$ Figures showing activity bundles for each subperiod are available upon request.
} 
market inputs can be combined in various ways to provide utility. Hence, his notion of utility is far more general than the standard assumption in the macroeconomics literature, in which total non-market time is often combined into a general notion of leisure time.

We formalize Becker's (1965) notion in a nested CES production function. Households combine time $l_{i}$ and market inputs $x_{i}$ in a CES production function to produce consumption of activity $i$, denoted by $c_{i}$. Household utility is defined over the combination of all activities and aggregated using CES preferences:

$$
u\left(c_{i}\right)=\log \left\{\left(\sum_{i} \alpha_{i} c_{i}^{\rho-1} \rho\right)^{\frac{\rho}{\rho-1}}\right\}, \quad c_{i}=\left(\kappa_{i} x_{i}^{\frac{\xi_{i}-1}{\tilde{\xi}_{i}}}+\left(1-\kappa_{i}\right) \ell_{i}^{\frac{\xi_{i}-1}{\xi_{i}}}\right)^{\frac{\xi_{i}}{\xi_{i}-1}}
$$

with $0 \leq \alpha \leq 1,0 \leq \kappa \leq 1, \rho \geq 0$, and $\xi_{i} \geq 0$. Four sets of parameters govern the utility function. First, $\alpha_{i}$ determines the relative weights of every activity in the overall set of activities. Second, $\rho$ captures the elasticity of substitution between these consumption activities. Third, for a given activity $i, \kappa_{i}$ determines the weight of market inputs in the production of every activity. Finally, the elasticity of substitution between market inputs and time is given by $\xi_{i}$. $\xi_{i}$ can vary across activities, implying that the extent to which households substitute between market inputs and their own time may differ across activities. This parsimonious way of modeling the production of activities yields a flexible arrangement in which time use and market inputs are combined.

Section 2 documents that consumption expenditures related to market work are virtually zero. Hence, we assume that market work does not require consumption expenditures. Each household has one unit of time that can be allocated to the production of non-market activities or market work. Let $w$ be the wage rate and $p_{i}$ the price of market input $x_{i}$ associated with activity $i$. The budget constraint is

$$
\sum_{i} p_{i} x_{i}=w\left(1-\sum_{i} \ell_{i}\right)
$$

Two model innovations distinguish our framework from more commonly used macroeconomic models and thus warrant further discussion. The first innovation is that non-market time- - the standard notion of leisure-is divided into sev- 
eral time segments and each segment is linked to the production of one activity. Hence, we depart from the standard assumption that all leisure hours are perfect substitutes. If leisure hours are imperfect substitutes, households care about the allocation of time segments to activities instead of the total time spent on leisure. The effect of this assumption is summarized by the optimal ratio of time to market inputs for activity $i$ :

$$
\frac{\ell_{i}}{x_{i}}=\left(\frac{p_{i}}{w}\right)^{\xi_{i}}\left(\frac{1-\kappa_{i}}{\kappa_{i}}\right)^{\xi_{i}} .
$$

Because $\xi_{i} \geq 0 \forall i$, an increase in wages leads to a decline in the input ratio $\frac{\ell_{i}}{x_{i}}$. The intuition is simple: Wage increases induce more market work and thus a reduction in non-market time $\ell_{i}$ spent on producing activity $i$. At the same time, the increase in income enables households to purchase additional market inputs $x_{i}$. As a result, households substitute market inputs for time. The magnitude of the substitution is governed by $\xi_{i}$. Since $\xi_{i}$ is activity-specific, so is the response of $\frac{\ell_{i}}{x_{i}}$ to wage increases. A higher elasticity, $\xi_{i}$, implies that time and market inputs are more substitutable, resulting in larger decreases in the non-market time segment $\ell_{i}$ and therefore a larger increase in market hours.

The second model innovation is the introduction of a large set of non-market activities. We depart from the common assumption in the home production and leisure production literature that all market inputs and non-market time engaged in home or leisure production are perfectly substitutable. For instance, these models assume that cable services are a perfect substitute for restaurant services and that time spent on watching TV can be perfectly substituted for time spent dining out. In contrast, the model inspired by Becker (1965) interprets watching TV and eating in a restaurant as two distinct activities that follow separate production processes. The second model innovation allows households to substitute among a larger set of activities. The quantitative effect of this channel on the allocation of time and market inputs is governed by the substitution parameter $\rho$.

Both model innovations are important for generating dispersion in hours worked. To demonstrate this point, we contrast the responsiveness of hours worked to wage changes in the model à la Becker (1965) with several model versions that lack either 
one or both model innovations. For ease of notation, we call the model presented in this section the Becker model.

\subsection{Relaxing Both Model Innovations}

We begin by presenting a model version that relaxes both model innovations. This takes us back to the most prevalent form of utility in the literature, which is why we refer to it as the Standard model. Households derive utility from total market consumption and enjoy total leisure time. To be consistent with the model laid out in the previous section, the utility function is given by a CES aggregator between consumption $x^{s}$ and leisure $\ell^{s}$ :

$$
u\left(x^{S}, \ell^{S}\right)=\log \left\{\left(\phi^{S}\left(x^{S}\right)^{\frac{\sigma^{S}-1}{\sigma^{S}}}+\left(1-\phi^{S}\right)\left(\ell^{S}\right)^{\frac{\sigma^{S}-1}{\sigma^{S}}}\right)^{\frac{\sigma^{S}}{\sigma^{S}-1}}\right\}
$$

where $\sigma^{S} \geq 0$ is the elasticity of substitution between consumption and leisure. After normalizing the price of consumption to one, the budget constraint is:

$$
x^{\mathcal{S}}=w\left(1-\ell^{S}\right)
$$

In the Standard model, the optimal allocation between time and market consumption is summarized by

$$
\frac{\ell^{s}}{x^{s}}=\left(\frac{1}{w}\right)^{\sigma^{s}}\left(\frac{1-\phi^{s}}{\phi^{s}}\right)^{\sigma^{s}}
$$

The response of $\frac{\ell^{s}}{x^{s}}$ to a wage change is determined by the elasticity parameter $\sigma^{s}$, which has a similar role as $\xi_{i}$ in the Becker model. The difference is that wage changes can now only influence the substitution between total consumption and total leisure. Hence, the effects of substituting between market inputs and time within an activity, as well as across activities, are both muted in the Standard model.

\subsection{Relaxing the Segmentation of Non-Market Time}

Differential responses of hours worked to wage changes in the Standard model and in the model inspired by Becker may be driven solely by the availability of differ- 
ent market inputs $x_{i}$ at different prices $p_{i}$. In this case, the division of non-market time into various time segments would not be important for the responsiveness of hours worked to wage changes. To shed light on this argument, we reintroduce variation in market inputs and prices and allow households to choose from multiple consumption goods. We assume that each good $x_{i}^{m}$ in this version of the model corresponds to the market input $x_{i}$ in the Becker framework and that prices $p_{i}$ are the same in both setups. We refer to this model as the Multiple Goods model.

Preferences are given by

$$
\begin{aligned}
u\left(X^{m}, \ell^{m}\right) & =\log \left\{\left(\phi^{m}\left(X^{m}\right)^{\frac{\sigma^{m}-1}{\sigma^{m}}}+\left(1-\phi^{m}\right)\left(\ell^{m}\right)^{\frac{\sigma^{m}-1}{\sigma^{m}}}\right)^{\frac{\sigma^{m}}{\sigma^{m}-1}}\right\} \\
X^{m} & =\left(\sum_{i} \mu_{i}\left(x_{i}^{m}\right)^{\frac{\eta-1}{\eta}}\right)^{\frac{\eta}{\eta-1}},
\end{aligned}
$$

where $\eta \geq 0$ is the elasticity of substitution between different goods and $\sigma^{m} \geq 0$ is the elasticity of substitution between composite consumption $X^{m}$ and leisure $\ell^{m}$.

The budget constraint is

$$
\sum_{i} p_{i} x_{i}^{m}=w\left(1-\ell^{m}\right)
$$

The optimal inputs ratio is given by

$$
\frac{\ell^{m}}{x_{i}^{m}}=\left(\frac{p_{i}}{w}\right)^{\sigma^{m}}\left(\frac{1-\phi^{m}}{\phi^{m}}\right)^{\sigma^{m}} .
$$

Similar to the Standard model, wage changes only influence the substitution between consumption and total leisure time, but not the substitution between market inputs and time within an activity. In contrast to the Standard model, the Multiple Goods model allows households to substitute among different types of consumption goods, and therefore takes price variations into consideration. Yet this model defines total non-market time as leisure and does not require the combination of time and market inputs to produce individual activities and therefore misses the first innovation in the Becker model. 


\subsection{Reducing the Number of Activities}

Combining time and market inputs à la Becker (1965) has inspired a large literature on home production and a much smaller literature on leisure production. However, the literature abstracts from the large heterogeneity among home (leisure) activities and lumps all time and market inputs for home (leisure) production together. To examine whether our results depend on the number of activities being modeled, we consider a version of the model with home production (non-market work plus child care) and leisure production only. We call this model the Two Activity model.

The functional form of the Two Activity model is the same as in the Becker model. Hence, the mechanism through which wage changes affect the allocation of time and expenditures is comparable. However, the quantitative effects may differ because now households can only substitute between two activities, and thus substitute between market inputs and time at a much coarser level.

\section{Estimation}

We estimate the Becker model using the constructed pseudo-panel on market inputs and time allocations by education. We include six activities in the estimation: non-market work, child care, watching TV, socializing, eating and personal care, and hobbies and entertainment. We choose not to include sleep, because expenditures on market inputs for sleep are close to zero for all education groups.

We supplement data on time use and market inputs with data on wages and market input prices for each activity between 2003 and 2014. We use the CPS-ORG to construct wages by education group. Wages are defined as the ratio between weekly earnings and weekly working hours. We then average wages by education group and year to match them with the pseudo-panel of time use and market inputs.

In the baseline specification of our model, we assume all households face the same input prices. ${ }^{6}$ We use the Consumer Price Index (CPI) from the BLS to con-

\footnotetext{
${ }^{6}$ We explore the effects of heterogeneous prices by education group in Section 5.4.
} 
struct relative prices between market inputs. For our sample period, the expenditure categories in the CPI and CEX are consistent, and therefore CPI data can be directly mapped onto our activity categories. ${ }^{7}$ We proceed in three steps. First, we compute expenditure shares at the household level using the most detailed level of expenditures available in the CEX. Second, we use these shares as weights to aggregate the corresponding CPI indices to a weighted price index at the household level for each of the six activities. Finally, we average across all households using CEX sample weights to find the aggregate price index for an activity in a given year. Sections A.4 and A.5 in the Appendix provide details of the construction of prices and wages.

We use a minimum-distance estimator to estimate the model parameters $\left\{\mathcal{\zeta}_{i}\right\}_{i=1}^{6}$, $\left\{\kappa_{i}\right\}_{i=1}^{6},\left\{\alpha_{i}\right\}_{i=1}^{6}$, and $\rho$. Given prices and wages, the estimation targets allocations of time use and market inputs from 2003 to 2014 for each activity by education group. Variation in household allocations by education and over time helps identify the estimated parameters. In the cross-section and over time, households face different wages and choose different allocations as a result. How allocations change as prices/wages change reflects substitutability across activities and between time and market inputs within activities. Standard errors are obtained by bootstrapping the household-level data sets. Following the same strategy, we estimate the model versions that mute one or both innovations of the Becker modelnamely, the Standard, Multiple Goods, and Two Activity models.

\subsection{Estimation Results}

This section discusses the estimation results. Table 2 summarizes the estimated parameters with standard errors in parentheses. Standard errors are small, implying that the parameters are precisely identified. Formal proof of identification is difficult, as the model is highly nonlinear. Instead, we examine the curvature of the minimized objective function in the neighborhood of the estimated parameter values. Changing one parameter at a time, Figure C.3 shows that the objective function indeed reaches its minimum at the estimated parameter values.

\footnotetext{
${ }^{7}$ We follow Casey (2010) to construct consistent categories between the CPI and CEX.
} 
Our first finding is that the activity-specific elasticities of substitution between market inputs and time $\left(\xi_{i}\right)$ are larger than one for all activities considered. This means that the optimal ratio of time to market inputs, as defined in equation (1), changes by more than the change in wages, and therefore implies that households react strongly to wage changes by reallocating time and expenditures within activities. Note that this reallocation is much larger than what a Cobb-Douglas specification would imply, where changes in wages would translate one-to-one into changes in the ratio of time to market inputs.

When inspecting the activity-specific elasticities more carefully, we observe that leisure-related activities exhibit the highest elasticities of substitution between time and market inputs. The activity socializing has an elasticity of substitution of 1.34, while watching TV, eating and personal care, and hobbies and entertainment have elasticities around two. The estimated elasticity of substitution for child care has a value of 2.30. The elasticity of substitution for non-market work is 1.10 .

One may argue that the non-market work elasticity seems to be low, compared with the elasticity estimates between market inputs and time from the home production literature. ${ }^{8}$ However, our modeling strategy and empirical mapping between model and data differ substantially from the literature, and therefore the activity-specific estimates are not directly comparable to estimates reported in the literature.

The first difference is the specific model structure we employ in this paper. To capture the notion laid out by Becker (1965), we propose a model that captures a large set of activities produced with non-market time and market inputs. Standard home production models lack such features. In these models, households only produce one activity, and all non-market time outside of home production is collapsed into one time segment called leisure.

The second difference is that the underlying definition of what constitutes a home production activity varies between the literature and our paper. For example, the activity of dining out-a substitute to homemade meals-is used to estimate

\footnotetext{
${ }^{8}$ Rupert et al. (1995) find an estimate between 1 and 1.8 depending on gender and marital status. McGrattan et al. (1997) estimate a value of 1.75. Chang (2003), Aguiar and Hurst (2007a) and Fang and Zhu (2017) report a value around 2.
} 
the elasticity of substitution between market goods and time in the home production literature. In our framework, in contrast, dining out belongs to the activity of eating and personal care. As a result, the substitutability between homemade meals and dining out is governed by the elasticity of substitution across activities, $\rho$, rather than the activity-specific elasticity, $\xi_{i}$. Because restaurant meals are a close to perfect substitute for homemade meals, this difference tends to drive down the estimate of $\xi_{i}$ for non-market work. Despite these two differences, our estimation results suggest that time and market inputs for home production are substitutes, which is consistent with the literature.

A second important finding is that the estimated shares of market inputs $\left(\kappa_{i}\right)$ vary across activities. Non-market work has by far the largest share (0.52) and child care has the smallest share (0.11). For the remaining leisure activities, market input shares range from 0.12 to 0.21 . Note that the estimated standard errors are small, which implies that the share of time inputs for every activity is significantly different from zero. This provides confidence in Becker's notion that households require a combination of market inputs and time to enjoy consumption of nonmarket activities.

Our third finding is that the weight of each activity $\left(\alpha_{i}\right)$ in the overall utility of households varies significantly. Non-market work has the largest weight of 0.28 and child care has the smallest weight of 0.08. More importantly, the combined leisure activities have a weight of 0.64, with each activity having a weight between 0.11 and 0.20 . The estimation thus suggests that leisure-related activities constitute an important component of household utility. Given this finding, it is not surprising that formalizing Becker's idea beyond home production significantly alters how households reallocate time and market inputs in response to wage changes.

Our final result suggests that consumption activities themselves are quite substitutable. The elasticity of substitution across activities, $\rho$, has an estimated value of 1.40. This large substitutability across activities is because households can optimize over a large set of activities. As we will show in section 4.2, reducing the number of activities drives down the parameter estimate for $\rho$. Thus, the degree of substitutability shrinks as the number of consumption activities declines. 
We check the fit of our model by confronting it with cross-sectional data on market input expenditures and time use for each activity. Tables 3 and 4 report average allocations by education group. The model replicates the expenditure and time use data fairly well.

Table 2: Parameter Estimates

\begin{tabular}{ccccccc}
\hline & Child & Non-market & TV & Social & Eat \& Pcare & Hobbies \\
\hline$\xi$ & 2.286 & 1.100 & 2.080 & 1.339 & 1.975 & 2.066 \\
& $(0.027)$ & $(0.020)$ & $(0.024)$ & $(0.013)$ & $(0.015)$ & $(0.018)$ \\
$\kappa$ & 0.109 & 0.518 & 0.122 & 0.207 & 0.184 & 0.183 \\
& $(0.001)$ & $(0.011)$ & $(0.000)$ & $(0.003)$ & $(0.001)$ & $(0.001)$ \\
$\alpha$ & 0.080 & 0.284 & 0.197 & 0.113 & 0.179 & 0.146 \\
& $(0.002)$ & $(0.005)$ & $(0.001)$ & $(0.001)$ & $(0.001)$ & $(0.001)$ \\
$\rho$ & 1.399 & & & & & \\
& $(0.027)$ & & & & & \\
\hline
\end{tabular}

Notes: The table reports the means of the bootstrapped distributions for the preference parameters of the model described in Section 3.1 (bootstrapped standard errors are in parentheses).

Table 3: Model Fit - Expenditure

\begin{tabular}{lllllll}
\hline \multicolumn{7}{c}{ Expenditure Share - Data } \\
\hline Educ & Child & Non-market & TV & Social & Eat \& Pcare & Hobbies \& Ent \\
1 & 0.011 & 0.674 & 0.039 & 0.085 & 0.099 & 0.091 \\
2 & 0.015 & 0.614 & 0.045 & 0.085 & 0.119 & 0.122 \\
3 & 0.020 & 0.577 & 0.042 & 0.084 & 0.141 & 0.136 \\
4 & 0.027 & 0.549 & 0.037 & 0.076 & 0.162 & 0.149 \\
\hline \multicolumn{7}{c}{ Expenditure Share - Model } \\
\hline Educ & Child & Non-market & TV & Social & Eat \& Pcare & Hobbies \& Ent \\
1 & 0.013 & 0.655 & 0.031 & 0.087 & 0.107 & 0.107 \\
2 & 0.017 & 0.617 & 0.038 & 0.083 & 0.124 & 0.120 \\
3 & 0.018 & 0.599 & 0.042 & 0.082 & 0.132 & 0.126 \\
4 & 0.025 & 0.544 & 0.054 & 0.076 & 0.156 & 0.143 \\
\hline
\end{tabular}

Notes: The top panel reports expenditure shares data (average from 2003-2014). The bottom panel reports the model's fitted values for the expenditure shares at the estimated parameter values. Households are grouped into four education groups: 1 - less than high school, 2 - high school, 3 some college, 4 - college and above.

\subsection{Estimation Results for Alternative Models}

Table 5 reports the estimation results for the Standard, Multiple Goods and Two Activity models discussed in Sections 3.2-3.4. The alternative model specifications lack one or both of the innovations the Becker model. 
Table 4: Model Fit - Time

\begin{tabular}{lllllll}
\hline \multicolumn{7}{c}{ Time - Data } \\
\hline Educ & Child & Non-market & TV & Social & Eat \& Pcare & Hobbies \& Ent \\
1 & 0.047 & 0.173 & 0.203 & 0.064 & 0.102 & 0.069 \\
2 & 0.040 & 0.165 & 0.181 & 0.066 & 0.112 & 0.078 \\
3 & 0.042 & 0.160 & 0.148 & 0.067 & 0.119 & 0.085 \\
4 & 0.051 & 0.153 & 0.114 & 0.061 & 0.129 & 0.094 \\
\hline \multicolumn{7}{c}{} \\
\hline \multirow{2}{*}{ Educ } & Child & Non-market & TV & Social & Eat \& Pcare & Hobbies \& Ent \\
1 & 0.049 & 0.163 & 0.173 & 0.067 & 0.130 & 0.093 \\
2 & 0.047 & 0.164 & 0.166 & 0.066 & 0.120 & 0.085 \\
3 & 0.045 & 0.164 & 0.162 & 0.065 & 0.115 & 0.081 \\
4 & 0.040 & 0.164 & 0.149 & 0.062 & 0.097 & 0.068 \\
\hline
\end{tabular}

Notes: The top panel reports the share of time use in the data (average from 2003-2014). The bottom panel reports the model's fitted values for the same time use values at the estimated parameter values. Households are grouped into four education groups: 1 - less than high school, 2 - high school, 3 - some college, 4 - college and above.

First, consider the Standard model, which prevents households from allocating non-market time to a set of different activities and does not require them to combine market inputs and time at the activity level. The elasticity of substitution between market inputs and time $\sigma^{s}$ is 1.25 in the standard model. In contrast, the Becker model suggests a much larger degree of substitutability, especially for leisure-related activities. This is not surprising, because in the Becker model the substitution is between market inputs and time for a single activity, while in the Standard model the substitution is between total expenditures on all market inputs and total non-market time.

The finding of low elasticity in the Standard model is replicated by the estimation results of the Multiple Goods model. In fact, the substitutability between market inputs and time $\sigma^{m}$ is almost identical as in the Standard model. This finding is important for two reasons. First, it shows that accounting for the variation in market input prices alone does not alter the responsiveness of hours worked to wage changes. Second, the division of market inputs into different categories does not drive the results implied by the Becker model. Key to our findings is that enjoying non-market activities requires a combination of time and market inputs.

The Two Activity model reintroduces this key feature while limiting the number of activities to home production and leisure. The estimated elasticity of sub- 
stitution for home production is close to 1.10, and therefore comparable to the estimate in the Becker model. Note, however, that collapsing all leisure activities into a single activity reduces the elasticity of substitution between market inputs and time to 1.59 , which is well below the estimates implied by the Becker model. In addition, the elasticity of substitution across activities $\rho$ shrinks by more than half to 0.67 when the number of activities is collapsed to two. This is intuitive, because finer activity categories will necessarily imply a larger degree of substitutability across activities. The low elasticities of substitution suggest that the response of hours worked to wage changes in the Two Activity model will be limited.

Table 5: Parameter Estimates for Alternative Models

\begin{tabular}{|c|c|c|c|c|c|c|}
\hline \multicolumn{7}{|c|}{ A. Standard Model } \\
\hline$\sigma^{\mathcal{S}}$ & $\begin{array}{c}1.252 \\
(0.017)\end{array}$ & & & & & \\
\hline$\phi^{S}$ & $\begin{array}{c}0.287 \\
(0.005) \\
\end{array}$ & & & & & \\
\hline \multicolumn{7}{|c|}{ B. Multiple Goods Model } \\
\hline & Child & Non-market & $\mathrm{TV}$ & Social & Eat \& Pcare & Hobbies \\
\hline$\mu$ & $\begin{array}{c}0.025 \\
(0.001)\end{array}$ & $\begin{array}{c}0.556 \\
(0.004)\end{array}$ & $\begin{array}{c}0.055 \\
(0.001)\end{array}$ & $\begin{array}{c}0.087 \\
(0.000)\end{array}$ & $\begin{array}{c}0.143 \\
(0.001)\end{array}$ & $\begin{array}{c}0.134 \\
(0.001)\end{array}$ \\
\hline$\eta$ & $\begin{array}{c}1.128 \\
(0.012)\end{array}$ & & & & & \\
\hline$\sigma^{m}$ & $\begin{array}{c}1.255 \\
(0.017)\end{array}$ & & & & & \\
\hline$\phi^{m}$ & $\begin{array}{c}0.351 \\
(0.002) \\
\end{array}$ & & & & & \\
\hline \multicolumn{7}{|c|}{ C. Two Activity Model } \\
\hline & Home & Leisure & & & & \\
\hline$\xi$ & $\begin{array}{c}1.078 \\
(0.021)\end{array}$ & $\begin{array}{c}1.596 \\
(0.017)\end{array}$ & & & & \\
\hline$\kappa$ & $\begin{array}{c}0.484 \\
(0.011)\end{array}$ & $\begin{array}{c}0.179 \\
(0.001)\end{array}$ & & & & \\
\hline$\alpha$ & $\begin{array}{c}0.458 \\
(0.004)\end{array}$ & $\begin{array}{c}0.542 \\
(0.004)\end{array}$ & & & & \\
\hline$\rho$ & $\begin{array}{c}0.673 \\
(0.036)\end{array}$ & & & & & \\
\hline
\end{tabular}

Notes: The table reports the means of the bootstrapped distributions for the preference parameters of the three alternative models described in Sections 3.2, 3.3 and 3.4, respectively. Bootstrapped standard errors are shown in parentheses. 


\section{Results}

\subsection{Dispersion in Hours Worked}

This section compares the model-implied cross-sectional dispersion in hours worked with the data. Recall that dispersion in wages is the only source of heterogeneity in all models. To this end, we take the wage distribution from the CPS-ORG in each survey year as exogenous. We also take the activity-specific prices of market inputs as given. Table 6 reports the model-implied dispersion in hours worked in levels and as a percentage of the dispersion in the data. Given that dispersion varies very little between 2003 and 2014, we only report averages across all years.

Table 6: Dispersion in Hours Worked - Data vs. Models

\begin{tabular}{lcc}
\hline & Dispersion & $\begin{array}{c}\text { Dispersion } \\
\text { (as \% of data) }\end{array}$ \\
\hline Data & 0.439 & 1.000 \\
Becker & 0.239 & 0.545 \\
Standard & 0.122 & 0.278 \\
Multiple Goods & 0.128 & 0.292 \\
Two Activity & 0.140 & 0.319 \\
\hline
\end{tabular}

We observe that the Standard, Multiple Goods, and Two Activity models perform poorly and generate only $30 \%$ of the hours dispersion observed in the data. The Becker model, on the other hand, generates $55 \%$ of the dispersion in the data, roughly double the quantitative effect of other models.

Recall that Section 3 emphasized two innovations in the Becker model: (1) dividing non-market time into activity-specific time segments and combining each segment with activity-specific market inputs; (2) expanding the set of non-market activities that households derive utility from. Both model innovations are key for the quantitative results. This follows from households in the Becker model having additional margins of substitution available to them, i.e., the substitution between market inputs and time within each activity and over a large set of activities. Because the estimated elasticities of substitution $\left(\xi_{i}\right.$ and $\rho$ ) for these margins are large, 
households are willing and able to substitute across these extra margins and thus can allocate market inputs and time much more flexibly. As a result, variation in wages leads to a much larger dispersion in hours worked relative to models that lack these features.

If we shut down the first model innovation, we are back to the case of the Standard and Multiple Goods models. Neither model requires households to combine market inputs and time to produce an activity. Eliminating this model innovation causes the implied hours dispersion to shrink by half. This finding demonstrates that the division of time into activity-specific components is essential for our key result, while the division of expenditures into activity-specific components is not. In fact, even if we include the same number of market inputs, but do not segment non-market time into different activities (i.e. the Multiple Goods model), the implied hours dispersion is as low as in the Standard model.

We also assess to what extent our results are driven by the second model innovation, that is, the nuber of activities being modeled. The Two Activity model encompasses the first model innovation, but reduces the number of activities from six to two. It generates a slightly larger dispersion in hours worked than the Standard and Multiple Goods models, confirming the finding that the combination of market inputs and time at the activity level is key for generating hours dispersion. However, the hours dispersion generated by the Two Activity model is still well below that in the Becker model. Two estimation results are responsible for this outcome. First, the estimation suggests that if one divides non-market activities into just home and leisure production, the elasticity of substitution across activities, $\rho$, shrinks by half. Second, the estimated elasticity of substitution between market inputs and time for leisure, $\xi_{i}$, is well below the estimates for leisure-related activities in the Becker model. Thus the substitution between market inputs and time is much more limited in the Two Activity model. Taken together, these findings imply that wage dispersion leads to much lower hours dispersion in the Two Activity model than in the Becker model.

One could argue that the number of activities should be increased even further than the six activities we propose in this paper. While we agree with this statement, 
data constraints prevent us from modeling a finer breakdown of activities in a meaningful way. The six activities we use are distinct, and thus the measurement error from misclassification is not severe. Increasing the number of activities is likely to bring the model-implied hours dispersion closer to the data, but it would also lead to larger measurement errors due to inconsistent classification between market inputs and time categories. Given this challenge, we opt for the time use classification in the literature and use six well-defined non-market activities to perform our study. We leave the study of more activities for future work.

\subsection{Hours Worked and Wages}

To shed light on the underlying mechanism that generates much more hours dispersion in the Becker model, we simulate the response of hours worked to a series of wage changes. For each model, we take the hours worked implied by the average wage for each education group and the average price for each activity between 2003 and 2014 as the baseline. We then increase wages successively up to $100 \%$ with prices held constant at baseline levels. Figure 3 compares the response of hours worked to wage changes in the four models.

Consistent with our intuition, wage increases result in more pronounced changes in hours worked in the Becker model relative to the other models. In fact, the response in the Becker model is roughly twice as large as that in the Standard or Multiple Goods models. This is consistent with the result that the Becker model generates twice as much hours dispersion. Note that the hours responses are quite similar across education groups within each model. Thus, the Becker model accounts for a roughly equal amounts of hours dispersion within each education group.

\subsection{Model Validation}

We further validate the underlying mechanism in the Becker model by demonstrating that the model-implied correlations between wages and market inputs are consistent with the data. To this end, we regress household-level expenditure shares for each activity on log wages and compare the results with the same regression 
Figure 3: Response of Hours Worked to a Percentage Wage Change

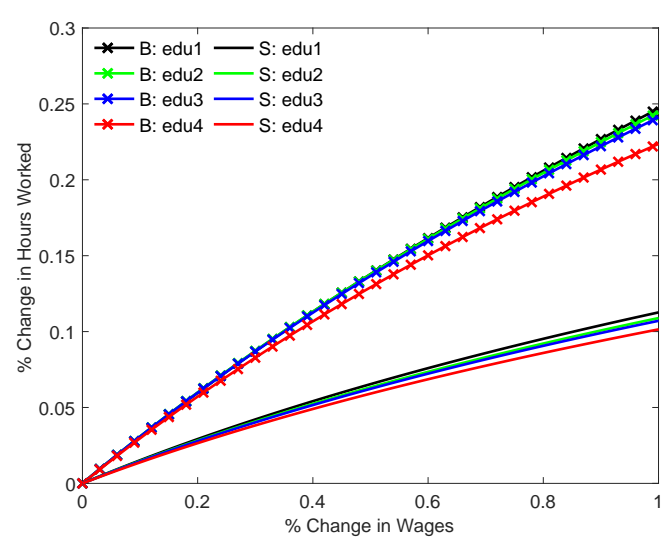

(a) Becker vs. Standard

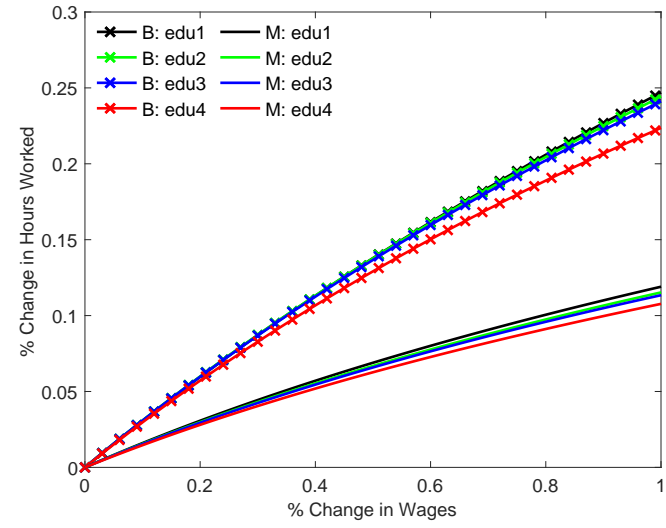

(b) Becker vs. Multiple Goods

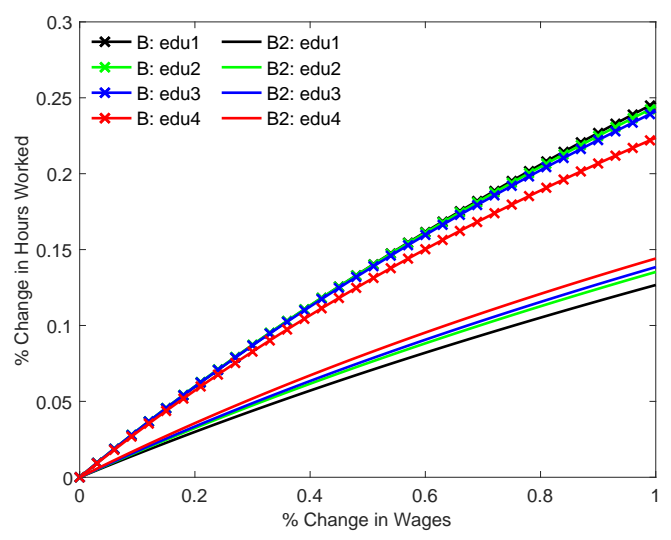

(c) Becker vs. Two Activity

Notes: 'B' refers to the Becker model, 'S' to the Standard model, ' $\mathrm{M}$ ' to the Multiple Goods model, and 'B2' to the Two Activity model. The four education categories are defined as follows: edu1 - less than high school, edu2 - high school, edu3 - some college, edu4 - college and above.

using model simulated data. ${ }^{9}$ We could not perform this exercise for time use, because income is only reported in wide-ranged brackets and not as a continuous variable in the ATUS.

Table 7 compares the regression results in the model and in the data. The model-predicted responses of expenditure shares to wage changes are consistent with the data for every activity. The estimates, in both the model and the data, are estimated with a high degree of precision.

\footnotetext{
${ }^{9}$ In the regressions, we control for age, race, marital status, number of children, education, and time trend.
} 
Table 7: Regression of Expenditure Shares on Wages

\begin{tabular}{lrr}
\hline & \multicolumn{1}{c}{ Data } & \multicolumn{1}{c}{ Model } \\
\hline Child Care & $0.0023^{* * *}$ & $0.0131^{* * *}$ \\
& $(0.0001)$ & $(0.0000)$ \\
Non-Market Work & $-0.0215^{* * *}$ & $-0.1024^{* * *}$ \\
& $(0.0003)$ & $(0.0000)$ \\
Watching TV & $0.0004^{* * *}$ & $0.0246^{* * *}$ \\
& $(0.0001)$ & $(0.0000)$ \\
Socializing & $0.0020^{* * *}$ & $-0.0075^{* * *}$ \\
& $(0.0001)$ & $(0.0000)$ \\
Eating \& Personal Care & $0.0131^{* * *}$ & $0.0370^{* * *}$ \\
& $(0.0002)$ & $(0.0000)$ \\
Hobbies \& Entertainment & $0.0074^{* * *}$ & $0.0351^{* * *}$ \\
& $(0.0003)$ & $(0.0000)$ \\
\hline
\end{tabular}

Notes: The dependent variable is expenditure share and the regressor is log wage. The symbol ${ }^{* * *}$ represents significance at the 0.001 level.

\subsection{Education-Specific Prices}

So far, we have assumed that all households face the same market input price for a given activity. However, households may face different prices because they use different types of goods or services to produce the same activity. For instance, rich households may hire a maid to clean their houses while poor households buy cleaning supplies to do the work themselves. It follows that the input price of nonmarket work for rich households is more sensitive to maid services, while the price for poor households is more sensitive to cleaning supplies. To address this issues, we derive market input prices for each activity that vary by education group. The procedure is the same as before, except that we now average household prices at the education level. We reestimate the model and repeat the analyses in Sections 5.1 and 5.2 using education-specific prices. Table D.6 in the Appendix shows that the results for hours dispersion are virtually identical to the case with uniform prices.

There are other reasons households may face different prices. One example is that they consume the same type of goods but of different qualities. For instance, rich households may consume food from high-end stores while poor households may consume the same type of food from cheaper stores. Capturing such price differences requires price and household-level expenditure data for the same product 
consumed at different qualities. To the best of our knowledge, such data are not available, except for a small subset of goods. ${ }^{10}$

\section{Conclusion}

We formalize the notion of Becker (1965), in which households derive utility from combining time and market inputs, to study the implications of wage changes for hours worked. Our innovation is to divide households' time outside the market into a large number of time segments. Each segment is combined with specific market inputs to produce an activity households enjoy. In this framework, households respond more flexibly to wage changes because they can substitute between market inputs and their own time, both within and across a given set of activities. To demonstrate the quantitative importance of this model innovation, we combine consumption expenditure data from the CEX with data on time allocation from the ATUS for a set of six non-market activities. We construct a pseudo-panel and use it to estimate the proposed model. We find that the estimated model generates crosssectional dispersion in hours worked that is twice as large as alternative models. The alternative models either lack the interaction between time and market inputs at the activity level or reduce the number of activities being produced.

The model explored in this paper can be applied to a wide range of economic issues. For example, we did not consider changes in time and market input allocations over the lifecycle. The rich structure of our framework can be useful in analyzing the substantial allocation changes that occur before and after retirement. Another promising area is the study of welfare inequality. A proper measure of welfare should take into account the complexity of consumption bundles and their heterogeneity across different household types. The model proposed in this paper contains these elements and can therefore shed new light on the degree of welfare inequality in the economy. Finally, the model can be useful for understanding the cyclical movement of the "labor wedge," which measures empirical deviations in the marginal rate of substitution between consumption and leisure and the wage

\footnotetext{
${ }^{10}$ See Jaimovich et al. (2019) for an analysis of the phenomenon whereby the quality of consumption goods drops during recessions.
} 
rate. The standard economic approach lumps all market inputs and all non-market time together, and thus does not properly measure the marginal rate of substitution between consumption and leisure; this results in substantial labor wedges. The Becker framework can help improve measurements of the labor wedge and potentially account for its cyclical movement. We leave these questions for future research. 


\section{References}

Aguiar, M., Bils, M., Charles, K. and Hurst, E. (2019). Leisure Luxuries and the Labor Supply of Young Men. manuscript.

Aguiar, M. and Hurst, E. (2007a). Life-Cycle Prices and Production, American Economic Review 97(5): 1533-1559.

Aguiar, M. and Hurst, E. (2007b). Measuring Trends in Leisure: The Allocation of Time over Five Decades, The Quarterly Journal of Economics 122(3): 969-1006.

Aguiar, M., Hurst, E. and Karabarbounis, L. (2012). Recent Developments in the Economics of Time Use, Annual Review of Economics 4(1): 373-397.

Aguiar, M., Hurst, E. and Karabarbounis, L. (2013). Time Use during the Great Recession, American Economic Review 103(5): 1664-96.

Becker, G. S. (1965). A Theory of the Allocation of Time, The Economic Journal 75(299): 493-517.

Benhabib, J., Rogerson, R. and Wright, R. (1991). Homework in Macroeconomics: Household Production and Aggregate Fluctuations, Journal of Political Economy 99(6): 1166-1187.

Bils, M., Chang, Y. and Kim, S.-B. (2012). Comparative Advantage and Unemployment, Journal of Monetary Economics 59(2): 150-165.

Boerma, J. and Karabarbounis, L. (2019a). Inferring Inequality with Home Production. manuscript.

Boerma, J. and Karabarbounis, L. (2019b). Labor Market Trends and the Changing Value of Time. working paper.

Bopphart, T. and Ngai, R. (2019). Rising Inequality and Trends in Leisure. CEPR DP 12325.

Bridgman, B. (2016). Engines of Leisure. BEA Working Papers 0137, Bureau of Economic Analysis. 
Casey, W. (2010). CPI Requirements of CE, BLS Documentation .

Chang, Y. (2003). Labor-supply Shifts and Economic Fluctuations, Journal of Monetary Economics 50(8): 1751-1768.

Fang, L. and Zhu, G. (2017). Time Allocation and Home Production Technology, Journal of Economic Dynamics and Control 78: 88-101.

Greenwood, J. and Hercowitz, Z. (1991). The Allocation of Capital and Time over the Business Cycle, Journal of Political Economy 99(6): 1188-1214.

Heathcote, J., Storesletten, K. and Violante, G. L. (2014). Consumption and Labor Supply with Partial Insurance: An Analytical Framework, American Economic Review 104(7): 2075-2126.

Jaimovich, N., Rebelo, S. and Wong, A. (2019). Trading Down and the Business Cycle, Journal of Monetary Economics 102: 96-121.

Kaplan, G. (2012). Inequality and the life cycle, Quantitative Economics 3(3): 471525.

Kopecky, K. A. (2011). The Trend In Retirement, International Economic Review 52(2): 287-316.

McGrattan, E. R., Rogerson, R. and Wright, R. (1997). An Equilibrium Model of the Business Cycle with Household Production and Fiscal Policy, International Economic Review 38(2): 267-290.

Mustre del Rio, J. (2015). Wealth and Labor Supply Heterogeneity, Review of Economic Dynamics 18(3): 619-634.

Ngai, R. L. and Pissarides, C. A. (2011). Taxes, Social Subsidies, and the Allocation of Work Time, American Economic Journal: Macroeconomicss 3(4): 1-26.

Ngai, R. and Petrongolo, B. (2017). Gender Gaps and the Rise of the Service Economy, American Economic Journal: Macroeconomics 9(4): 1-44. 
Rupert, P., Rogerson, R. and Wright, R. (1995). Estimating Substitution Elasticities in Household Production Models, Economic Theory 6(1): 179-193.

Vandenbroucke, G. (2009). Trends in hours: The U.S. from 1900 to 1950, Journal of Economic Dynamics and Control 33(1): 237-249. 


\section{Online Appendix (Not for Publication)}

\section{A Data for Estimation}

\section{A.1 American Time Use Survey 2003-2014}

Following Aguiar et al. (2013), we divide the total time for every individual in the American Time Use Survey (ATUS) into 14 categories. These categories can be aggregated into four main time use categories: "market work", "non-market work", "child care" and "leisure". Market work includes time spent on working, commuting and job search. "Non-market work" includes core home production, home ownership activities, obtaining goods and services as well as care for others. "Leisure" summarizes time spent on watching TV, socializing, sleeping, eating and personal care, and hobbies and entertainment.

Table A.1 documents the activities for each time use category and table A.2 summarizes the underlying ATUS activity codes for these categories. ATUS indicates whether a time diary was recorded on a weekday or a weekend (or holiday). To obtain a representative estimate of the weekly hours allocated to one activity, we weight weekday records by $\frac{5}{7}$ and weekend or holiday records by $\frac{2}{7}$.

Table A.1: ATUS 2003-2014 Categorization

\begin{tabular}{|c|c|}
\hline ATUS Category & Description of Time Use \\
\hline \multicolumn{2}{|c|}{ I. Time Use Categories Used in the Analysis } \\
\hline Market Work & $\begin{array}{l}\text { Market Work } \\
\text { Other Income-Generating Activities } \\
\text { Job Search }\end{array}$ \\
\hline Child Care & Child Care \\
\hline Non-market Work & $\begin{array}{l}\text { Core Home Production } \\
\text { Home Ownership } \\
\text { Obtaining goods and services } \\
\text { Other Care }\end{array}$ \\
\hline Leisure & $\begin{array}{l}\text { Watching TV } \\
\text { Socializing } \\
\text { Sleep } \\
\text { Eating and Personal Care } \\
\text { Hobbies and Entertainment }\end{array}$ \\
\hline \multicolumn{2}{|c|}{ II. Other Time Use Categories } \\
\hline & $\begin{array}{l}\text { Education } \\
\text { Civic } \\
\text { Own Medical } \\
\text { Unclassified }\end{array}$ \\
\hline
\end{tabular}


Table A.2: ATUS 2003-14 Categorization: Activity Codes

\begin{tabular}{|c|c|}
\hline ATUS Category & ATUS Activity Code \\
\hline \multicolumn{2}{|c|}{ I. Time Use Categories Used in the Analysis } \\
\hline 1. Market Work & $\begin{array}{l}\text { 05-01, 05-02, 05-99, 18-05-01, 18-05-02, 18-05-99, 05-03, } \\
18-05-03,05-04,18-05-04\end{array}$ \\
\hline 2. Child Care & $\begin{array}{l}03-01,03-02,03-03,04-01,04-02,04-03,18-03-01,18-03- \\
02,18-03-03,18-04-01,18-04-02,18-04-03\end{array}$ \\
\hline \multicolumn{2}{|l|}{ 3. Non-market Work } \\
\hline 3.1 Core Home Production & $\begin{array}{l}\text { 02-01, 02-02, 02-03 (excl. 02-03-01), 02-07, 02-08, 02-09 } \\
\text { (excl. 02-09-03), 02-09-04, 02-99, 18-02-01, 18-02-02, 18- } \\
\text { 02-03, 18-02-07, 18-02-08, 18-02-09, 18-02-99 }\end{array}$ \\
\hline 3.2 Home Ownership Activities & $02-03-01,02-04,02-05,18-02-04,18-02-05$ \\
\hline 3.3 Obtaining Goods and Services & $\begin{array}{l}\text { 07, } 08 \text { (excl. 08-04), 09,10, 18-07, 18-08 (excl. 18-08-04), } \\
18-09,18-10\end{array}$ \\
\hline 3.4 Others Care & $\begin{array}{l}03-04,03-05,03-99,04-04,04-05,04-99,18-03-04,18-03- \\
05,18-03-99,18-04-04,18-04-05,18-04-99\end{array}$ \\
\hline \multicolumn{2}{|r|}{ (1) } \\
\hline 4.1 TV Watching & $12-03-03,12-03-04$ \\
\hline 4.2 Socializing & $\begin{array}{l}\text { 12-01, 12-02, 12-03-07, 12-05-01, 12-05-02, 16, 18-12-01, } \\
18-12-02,18-16\end{array}$ \\
\hline 4.3 Sleep & $01-01$ \\
\hline 4.4 Eating and Personal Care & $01-02,01-04,01-05,01-99,11,18-01,18-11$ \\
\hline 4.5 Hobbies and Entertainment & $\begin{array}{l}02-06,02-09-03,02-09-04,12-03 \text { (excl. 12-03-03 and 12- } \\
03-04), 12-03-07,12-04,12-05 \text { (excl. 12-05-01 and 12-05- } \\
02), 12-99,13,18-02-06,18-12 \text { (excl. 18-12-01 and 18-12- } \\
02), 18-13\end{array}$ \\
\hline \multicolumn{2}{|c|}{ II. Other Time Use Categories } \\
\hline 1. Education & "06,18-06 \\
\hline 2. Civic & $14,15,18-14,18-15$ \\
\hline 3. Own Medical & $01-03,08-04,18-08-04$ \\
\hline 4. Unclassified & $50,18-18,18-19$ \\
\hline
\end{tabular}

\section{A.2 Consumer Expenditure Survey 2003-2014}

The Consumer Expenditure Survey (CEX) consists of two components with separate questionnaires and independent samples. We use the Interview panel survey in which Consumer Units (CU) are interviewed once every three months over five consecutive quarters. The survey therefore records consumption expenditures for every CU over the period of one year. The data for the Interview panel is released in eight major data files for each wave separately. For this study, we make use of the FMLI and MTBI files.

To select households into our sample, we use the FMLI files which contain CU characteristics, CU income as well as earnings of the reference person and the spouse. Income data are collected on an annual basis during the second and 
the fifth interviews only. We therefore use information from the fifth interview to approximate labor income as well as the labor force status of the CU. We define a $\mathrm{CU}$ to be "in the labor force" if the reference person or the spouse report in their fifth interview that they worked at least one week during the last 12 months. If the information from the fifth interview is missing, we use the information from the second interview.

\section{A.3 Combining ATUS and CEX}

\section{A.3.1. Sample Selection}

We limit the sample in both the ATUS and CEX to reference persons between age 21 and 65, excluding students and retirees. We also restrict the sample to households with at least one spouse reported being "in the labor force". In the ATUS, this includes individuals being employed, absent from work, or unemployed either on layoff or looking for a job. This leaves us with 114,936 observations across all survey years in the ATUS.

The CEX only reports the number of weeks the reference person or the spouse have worked within the last 12 months. If either the reference person or the spouse reports to have worked at least one week, we include them in our sample. We impose additional restrictions on household income before calculating expenditure shares. First, we drop all households with zero or negative household income. Next, we drop households with income in the bottom and top $5 \%$ of the sample in every survey year. We lose 17,135 observations due to this restriction. The final CEX sample contains 148,152 observations.

\section{A.3.2. Linking ATUS and CEX}

To create consistent expenditure shares and time use associated with each activity, we start with the time-use activity categories discussed in section A.1 and map the associated consumption expenditure categories to the time use categories as closely as possible. The CEX releases detailed expenditure information in its MTBI files. Consumption and investment expenditures are organized by Universal Classification Codes (UCCs). The files contain approximately 600 different UCCs, with one record for every purchase of the $\mathrm{CU}$ in a given month. The Bureau of 
Labor Statistics (BLS) provides summary level variables that aggregate a certain set of UCCs. These summary variables serve as a guideline for the classification of expenditure categories. For every summary variable, we check the underlying UCCs and, if necessary, refine the categorization. Table A.3 provides a description of the expenditures associated with each category, while table A.4 documents the corresponding UCCs.

In additional to consumption expenditures, the CEX also collects information on the purchases and sales of assets. We classify the purchase and investment of housing and vehicles as separate categories, as they involve investment decisions and cannot be linked to a particular activity. Note that the investment categories only contain outlays related to the acquisition of new assets. Expenditures associated with the maintenance or repair of housing or vehicles, that the $\mathrm{CU}$ already owns, are matched with a corresponding time use category.

We exclude investment expenditures in the analysis for two reasons. First, they can not be linked to a specific time-use category. Second, the static model employed in this paper can not be used to analyze the investment decisions. Similarly, we exclude education and medical care time and expenditures from our main analysis as we view them as human capital investments. We exclude time spent on civic and unclassified activities because they can not be linked to any expenditure categories. Expenditures spent on transportation usage cannot be separated into direct transportation costs associated with actual activities. We therefore exclude it from our analysis as well. We refer to the expenditures included in our analysis as "core expenditures." Over the sample period, our measure of core expenditures accounts for slightly over one-half of all consumption expenditures reported in the CEX.

The ATUS and the CEX cannot be linked at the household level. We therefore link them either by education or income every year. We partition the observations into four education groups: less than high school, high school, some college, college and above. In both the ATUS and the CEX, the highest level of educational attainment of the reference person determines which education bin the household is assigned to. 
To partition data by household income, we first use the continuous information on family income before taxes from the CEX to construct weighted income quartiles in each survey year using survey weights. We drop negative incomes as well as the bottom and top 5\% of the income distribution. We find that the 25 th percentile is $\$ 26,600$, the 50 th percentile is $\$ 50,000$, the 75 th percentile is $\$ 83,900$. In the ATUS, combined income of all family members during the last 12 month is only reported in bins and not as a continuous variable. We thus chose the bins that most closely approximate the quartiles derived from the CEX. While we can match the 50th percentile exactly, we have to move the cut off points for the 25th and 75th percentile, so we can define income groups consistently across both data sets. The bin that encompasses the 75 th percentile in the CEX ranges from $\$ 75,000$ to $\$ 99,999$ in the CEX. Thus, we chose $\$ 99,999$ in both data sets as the cut off point for the highest income group (group 4). Similarly, we move the cut off for the 25th percentile to $\$ 25,000$ and define the lowest income group (group 1) as any family with income below this threshold.

Table A.3: CEX 2003-14 Categorization

\begin{tabular}{|c|c|}
\hline CEX Category & Description of Expenditures \\
\hline \multicolumn{2}{|r|}{ I. Core Expenditures } \\
\hline 1. Market Work & $\begin{array}{l}\text { Office furniture for home use; suits and uniforms for men and women; } \\
\text { personal digital assistants; meals received as pay; occupational expenses }\end{array}$ \\
\hline 2. Child Care & $\begin{array}{l}\text { Infant's equipment; babysitting and child day care; school books for day } \\
\text { care centers and nursery schools; school meals for preschool and school } \\
\text { age children }\end{array}$ \\
\hline \multicolumn{2}{|l|}{ 3. Non-market Work } \\
\hline $\begin{array}{l}\text { 3.1 Core Home Pro- } \\
\text { duction }\end{array}$ & $\begin{array}{l}\text { Utilities, fuels and public services (excl. telephone services); house- } \\
\text { hold textiles (excl. bedroom linens); furniture (excl. mattresses and new } \\
\text { springs); major appliances; small appliances; non-permanent carpet } \\
\text { squares; blinds; clocks; lamps; decorative items; kitchen utensils; house- } \\
\text { hold services; rental of furniture; rental of household and office equip- } \\
\text { ment for non-business use; management fees; other apparel products and } \\
\text { services (excl. watches and jewelry, clothing rental); food at home (excl. } \\
\text { food or board at school); other household expenses (excl. computers and } \\
\text { software for non-business use) }\end{array}$ \\
\hline 3.2 Home Ownership & $\begin{array}{l}\text { Maintenance, repairs and other expenses (excl. homeowner's insurance, } \\
\text { parking and management fees); floor coverings (excl. non-permanent car- } \\
\text { pet squares); installed and non-installed wall-to-wall carpeting; building } \\
\text { an attic, a pool or finishing the basement }\end{array}$ \\
\hline
\end{tabular}




\begin{tabular}{|c|c|}
\hline 3.3 Clothing & $\begin{array}{l}\text { Clothing for men and women (excl. suits and uniforms, nightwear, sports } \\
\text { coats, active sportswear, other sportswear and costumes); clothing for boys } \\
\text { and girls (excl. nightwear, active sportswear and costumes); clothing for } \\
\text { children (excl. sleeping garments); footwear; clothing rental }\end{array}$ \\
\hline 3.4 Other Care & $\begin{array}{l}\text { Care for invalids or elderly persons; adult care centers; care in nursing } \\
\text { home (net outlay) }\end{array}$ \\
\hline \multicolumn{2}{|l|}{ 4. Leisure } \\
\hline 4.1 Watching TV & $\begin{array}{l}\text { Cable services; TVs; video streaming; satellite dishes; repair, rental and } \\
\text { installation of TV and satellite equipment }\end{array}$ \\
\hline 4.2 Socializing & $\begin{array}{l}\text { Catered affairs; live entertainment; party supplies; telephone services and } \\
\text { devices; watches; jewelry; dating services }\end{array}$ \\
\hline 4.3 Sleep & Bedroom linens; mattresses and new springs; nightwear \\
\hline $\begin{array}{l}\text { 4.4 Eating and Per- } \\
\text { sonal Care }\end{array}$ & $\begin{array}{l}\text { Personal care appliances and services; rental and repair of personal care } \\
\text { appliances; food and beverages during out-of-town trips; alcoholic bever- } \\
\text { ages; dining out at restaurants }\end{array}$ \\
\hline $\begin{array}{l}4.5 \text { Hobbies and Enter- } \\
\text { tainment }\end{array}$ & $\begin{array}{l}\text { Trip expenditures on lodging; satellite radio services; video, radio and } \\
\text { sound equipment; records, CDs, videos and audio tapes; streaming audio } \\
\text { files; outdoor equipment; sport coats, sportswear and costumes; travel } \\
\text { items; rental or purchase of trailer-type camper, boat or aircraft; reading } \\
\text { (excl. encyclopedia); miscellaneous entertainment outlays; pets, toys and } \\
\text { playground equipment; musical instruments; photographic equipment; } \\
\text { event fees and admission; computers and software for non-business use; } \\
\text { tobacco and smoking supplies }\end{array}$ \\
\hline \multicolumn{2}{|r|}{ II. Other Expenditures } \\
\hline 1. Education & $\begin{array}{l}\text { Food or board at school; housing at school; private school bus; educational } \\
\text { expenses such as tuition and school books (excl. books for day care center); } \\
\text { encyclopedia; test prep and tutoring services; support for college students }\end{array}$ \\
\hline 2. Own Medical & $\begin{array}{l}\text { prescription drugs; health insurance; medical services (excl. care in nurs- } \\
\text { ing home); medical supplies }\end{array}$ \\
\hline 3. Transportation Usage & $\begin{array}{l}\text { Gasoline and motor oil, maintenance and repairs and vehicle insurance } \\
\text { for any type of vehicle; public transportation; vehicle registration; driver's } \\
\text { license; vehicle inspection; auto and truck or van rental; lease charges; } \\
\text { parking fees; tolls; vehicle equipment and services; GPS; automobile club } \\
\text { membership }\end{array}$ \\
\hline $\begin{array}{l}\text { 4. Transportation Owner- } \\
\text { ship }\end{array}$ & $\begin{array}{l}\text { Outlays for new, used and other vehicle purchases; outlays for motored } \\
\text { and non-motored recreational vehicles }\end{array}$ \\
\hline 5. Housing & $\begin{array}{l}\text { Rent of dwelling; ground rent; fire and extended coverage insurance; } \\
\text { homeowners' insurance; property taxes; mortgage interest; parking; rent } \\
\text { as pay }\end{array}$ \\
\hline 6. Home Investment Real & $\begin{array}{l}\text { Original carpeting; addition, alteration or new construction of dwellings; } \\
\text { New dishwasher, garbage disposal or range hood; Management, security, } \\
\text { parking; special assessment fees }\end{array}$ \\
\hline $\begin{array}{l}\text { 7. Home Investment Fi- } \\
\text { nancial }\end{array}$ & $\begin{array}{l}\text { Closing costs, special mortgage payments; reduction of mortgage princi- } \\
\text { pal; reduction of principal on home equity loan; special assessment for } \\
\text { roads, streets }\end{array}$ \\
\hline
\end{tabular}


Table A.4: CEX 2003-14 Categorization: UCCs

\begin{tabular}{|c|c|}
\hline CEX Category & Universal Classification Codes (UCCs) \\
\hline \multicolumn{2}{|r|}{ I. Core Expenditures } \\
\hline 1. Market Work & " 320901360110360901380510380902690115800700900002 \\
\hline 2. Child Care & 320130340211340212660901670310660900790430 \\
\hline \multicolumn{2}{|l|}{ 3. Non-market Work } \\
\hline $\begin{array}{l}\text { 3.1 Core Home Pro- } \\
\text { duction }\end{array}$ & 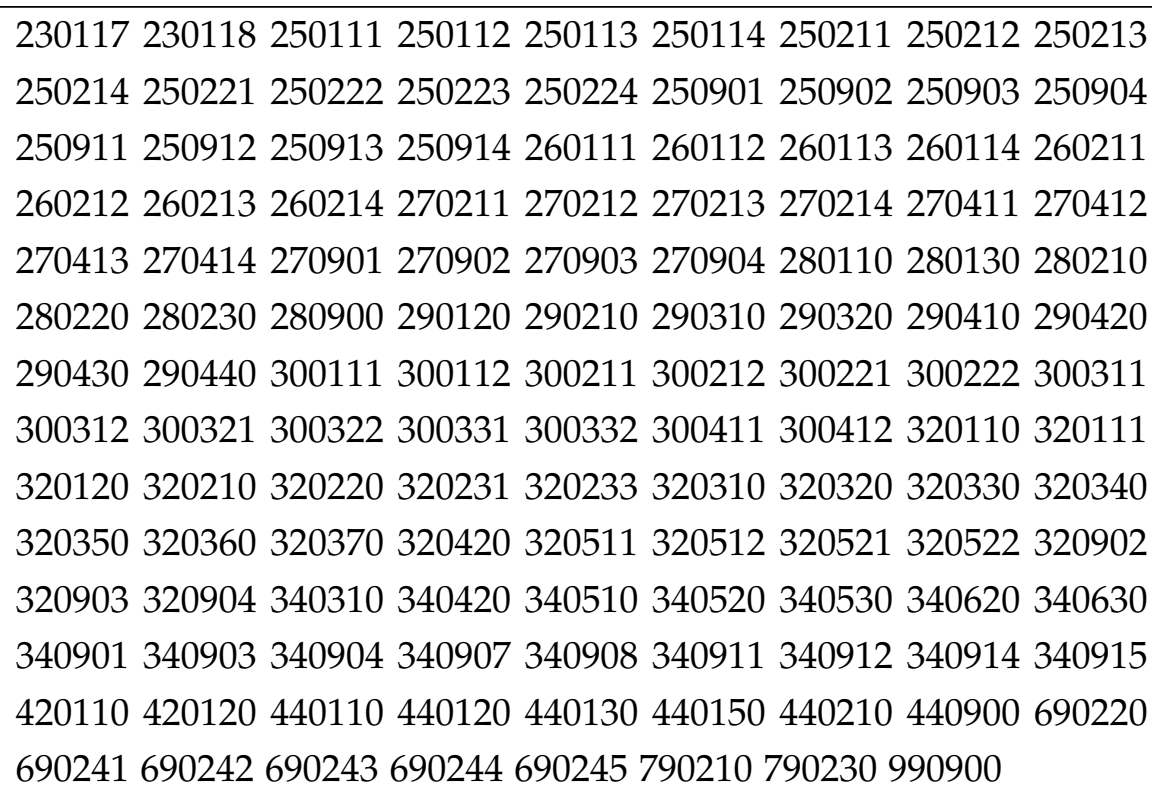 \\
\hline $\begin{array}{l}3.2 \text { Home Owner- } \\
\text { ship }\end{array}$ & 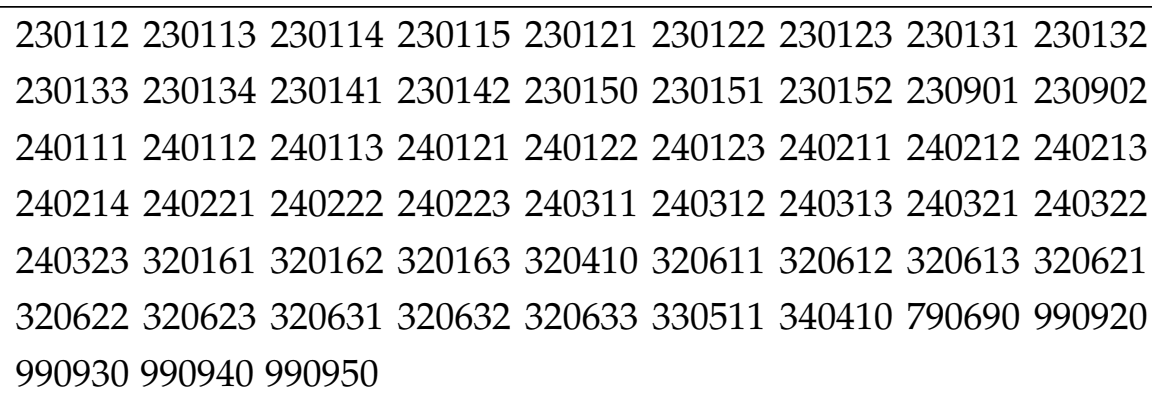 \\
\hline 3.3 Clothing & 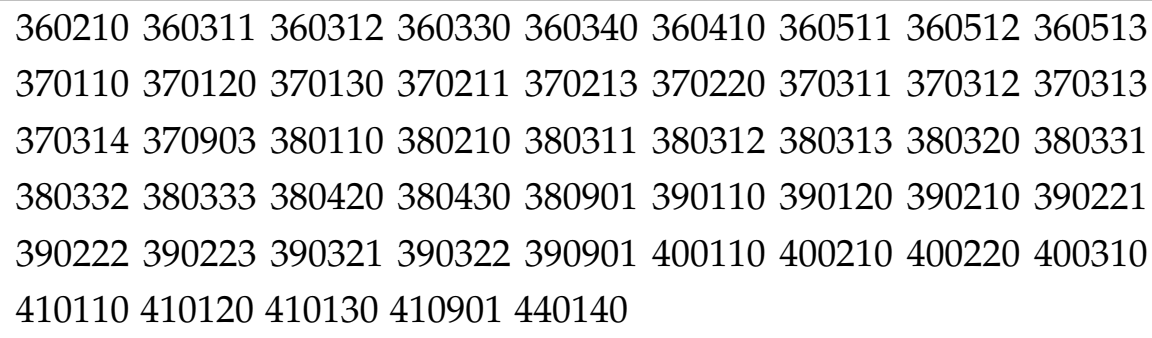 \\
\hline 3.4 Other Care & 340906340910570220 \\
\hline \multicolumn{2}{|l|}{ 4. Leisure } \\
\hline 4.1 Watching TV & $\begin{array}{l}270310310110310120310130310140310240310334340610340902 \\
690320690330\end{array}$ \\
\hline 4.2 Socializing & $\begin{array}{l}190902270101270102270103270104270105320232430110430120 \\
680310680320680904690210\end{array}$ \\
\hline 4.3 Sleep & 280120290110360320370212380410390310410140 \\
\hline
\end{tabular}




\begin{tabular}{|c|c|}
\hline $\begin{array}{l}\text { 4.4 Eating and Per- } \\
\text { sonal Care }\end{array}$ & $\begin{array}{l}640130640420650110650210650310650900190903190904200900 \\
790310790320790330790410790420\end{array}$ \\
\hline $\begin{array}{l}4.5 \text { Hobbies and En- } \\
\text { tertainment }\end{array}$ & 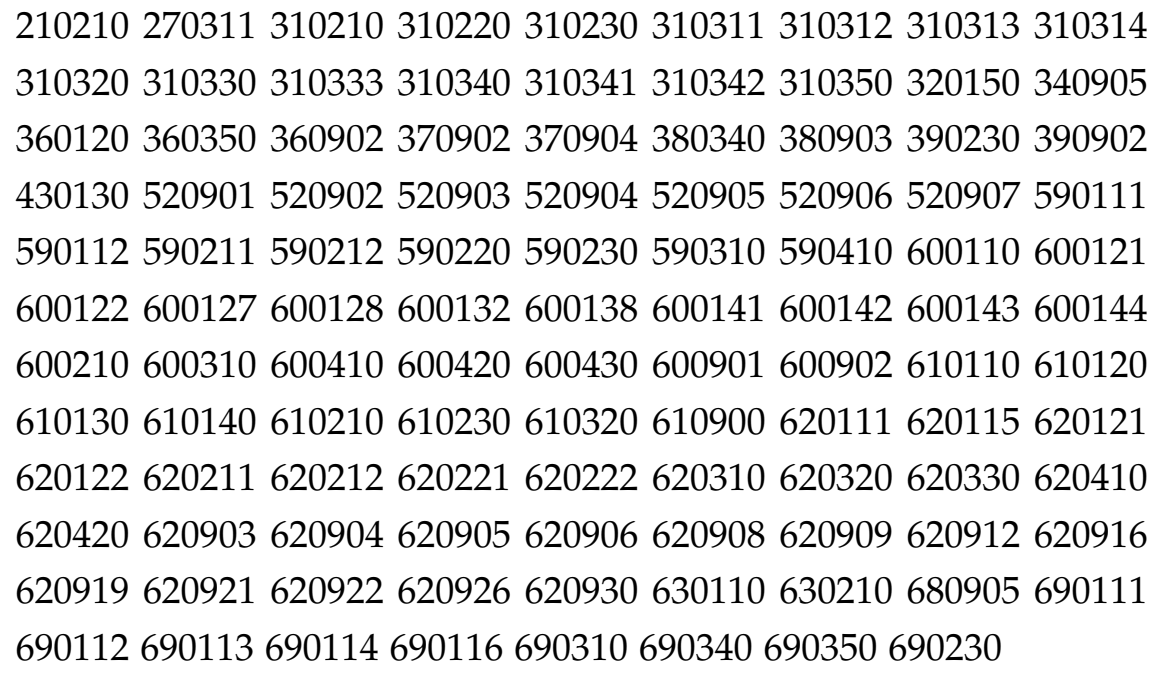 \\
\hline \multicolumn{2}{|r|}{ II. Other Expenditures } \\
\hline 1. Edu & $\begin{array}{l}190901210310530902660110660210 \\
6702106704106709016709026709038\end{array}$ \\
\hline 2. $\mathrm{Ow}$ & $\begin{array}{l}540000550110550320550330550340560110560210560310560330 \\
560400570110570111570210570230570240570901570903580111 \\
580112580113580114580311580312580400580901580903580904 \\
580905580906580907\end{array}$ \\
\hline $\begin{array}{l}\text { 4. Transportation Own- } \\
\text { ership }\end{array}$ & $\begin{array}{l}450311450411470111470112470113470211470212470220480110 \\
480213480214490110490211490212490221490231490232490311 \\
490312490313490314490318490319490411490412490413490501 \\
490502490900500110520110520111520112520310520410520511 \\
520512520521520522520531520532520542530110530210530311 \\
530312530411530412530510530901480212480215520541520550 \\
520560620113 \\
870101870102870103870104870201870202870203870204870301 \\
870302870303870304870401870402870403870404870501870502 \\
870503870504870605870606870607870608870701870702870703 \\
870704870801870802870803870804\end{array}$ \\
\hline 5. Housing & $\begin{array}{l}210110210901210902220111220112220121220122220211220212 \\
220311220312220901220902350110800710\end{array}$ \\
\hline $\begin{array}{l}\text { 6. Home Investment } \\
\text { Real }\end{array}$ & $\begin{array}{l}220511220512220513220611220612220615220616220614790600 \\
790610790611790620790630790640\end{array}$ \\
\hline $\begin{array}{l}\text { 7. Home Investment Fi- } \\
\text { nancial }\end{array}$ & $\begin{array}{l}790730790910^{*} 790920^{*} 790940^{*} 810301810302830101^{*} 830102^{*} \\
830201^{*} 830202^{*} 830203^{*} 830204^{*} 840101840102880120^{*} 880220^{*} \\
880320^{*}\end{array}$ \\
\hline
\end{tabular}


Notes: UCCs change across survey waves. In every quarter, UCCs might be discontinued while new ones are potentially added to the survey. In addition, new UCCs may not be represented in all quarters. This table reports the UCCs for all survey waves combined. We exclude UCC 790220 (Food and nonalcoholic beverage purchases at grocery stores) as it is a subset of UCC 790210 (Total purchases at grocery stores). We also exclude UCC 790240 (Average food and non-alcoholic beverage expenses) to avoid double counting of expenditures. To approximate expenditures related to the purchase of vehicles, we use UCCs 870101-870804. Since UCCs 450110-460908 also report costs associated with vehicle acquisitions, we drop them.

\section{A.4 Prices}

Disaggregated CPI indices are available for 398 expenditure categories between 2003 and 2014. We convert monthly CPI data into annual values by simply averaging over monthly observations. The data from CEX is a critical component for the CPI computations by the BLS. Thus, there is a direct mapping from UCC codes in the CEX to the disaggregated CPI indices. This mapping is provided in the Appendix B of Casey (2010).

After matching UCC codes to CPI indices, we compute a price index for the main and subcategories outlined in Table A.3 for each household in the CEX by weighting different CPI indices with their shares of expenditures within a category. We then average the prices for each category across households using the CEX sample weights. To compute education-specific prices, we follow the same procedure but average across households within a certain education group.

\section{A.5 Wages}

We use the CPS Outgoing Rotation Group (CPS-ORG) to compute wages. We use data between 2003 and 2014 and reference person between the ages of 21 65. We remove all topcoded and allocated observations. The CPS-ORG records hourly wages for hourly workers and weekly earnings for salary workers. We use the usual hours worked to derive the weekly earnings of hourly workers and compute household wages as the ratio between total weekly earnings and total weekly working hours of the household. If usual hours are unavailable, we use actual hours worked instead. We construct average wages for each of the four 
education groups in each year.

\section{B Stylized Facts by Income}

Figure B.1: Main Consumption Activities by Income

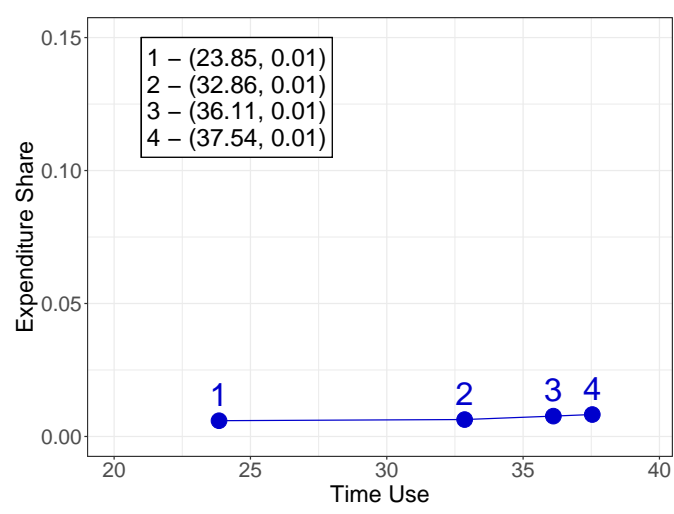

(a) Market Work

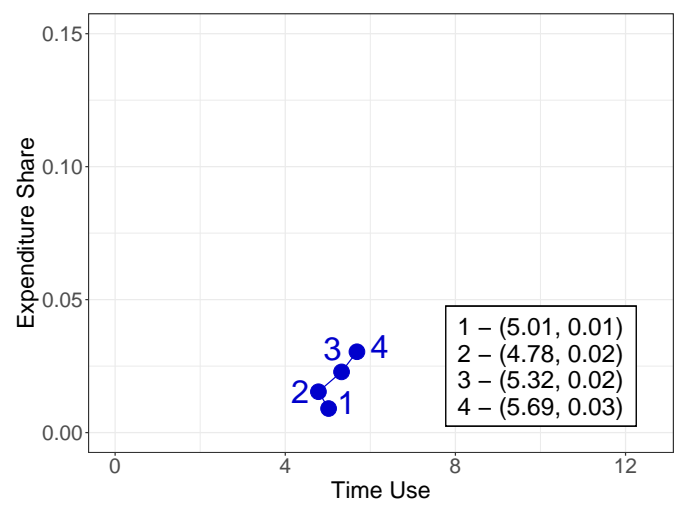

(c) Child Care

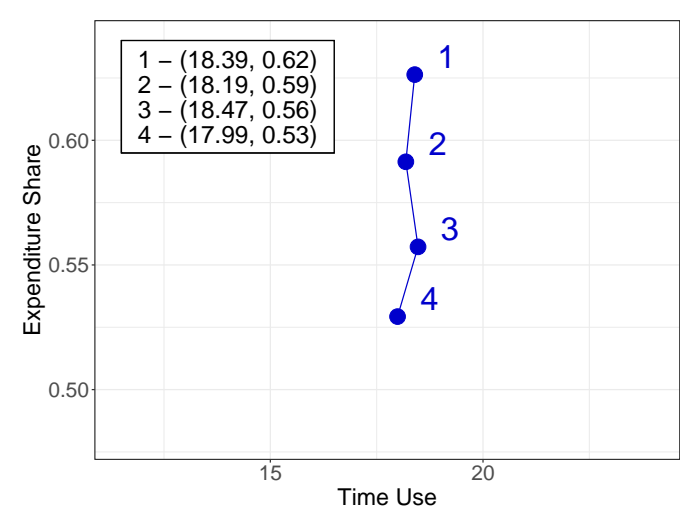

(b) Non-Market Work

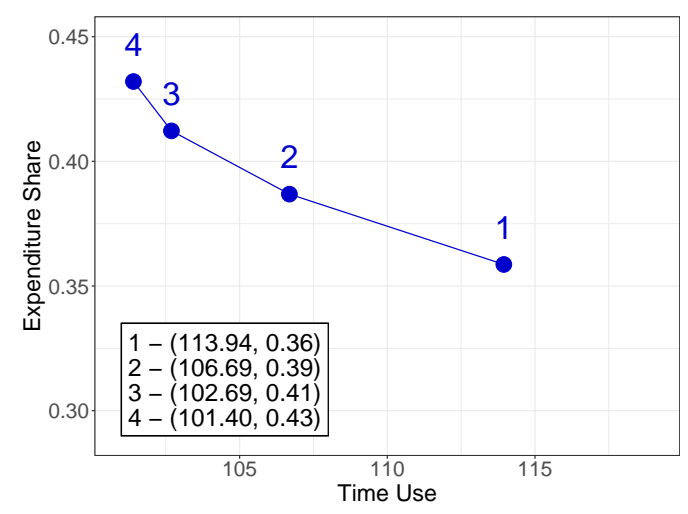

(d) Leisure

Notes: Households are grouped into income quartiles. Consumption expenditures are expressed as a fraction of core expenditures. Time use is reported as weekly hours. 
Figure B.2: Leisure Categories By Income

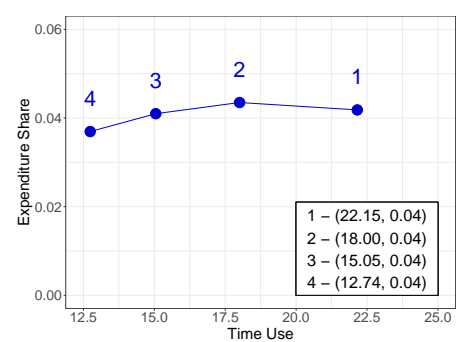

(a) Watching TV

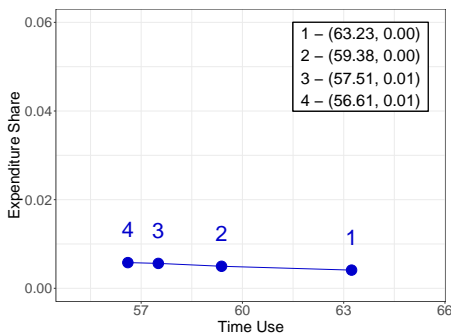

(b) Sleep

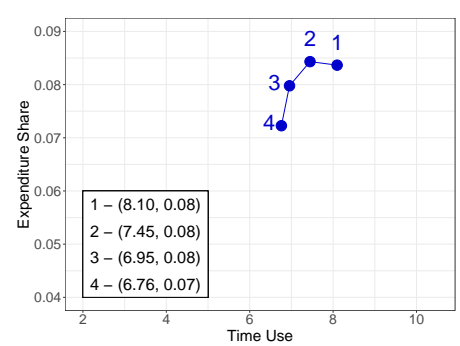

(c) Socializing

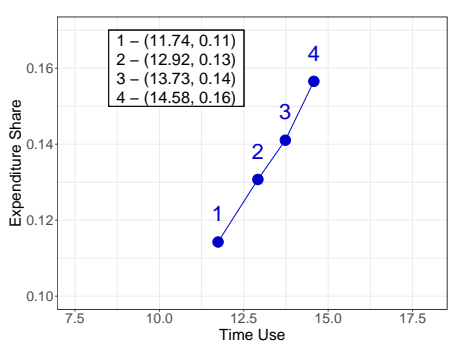

(d) Eating and Personal Care

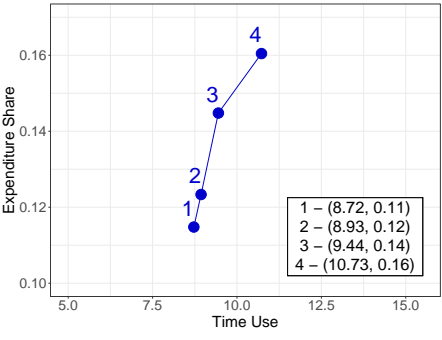

(e) Hobbies and Entertainment

Notes: Households are grouped into income quartiles. Consumption expenditures are expressed as a fraction of core expenditures. Time use is reported as weekly hours. 


\section{Identification of Parameters}

Figure C.3: Identification of Parameters
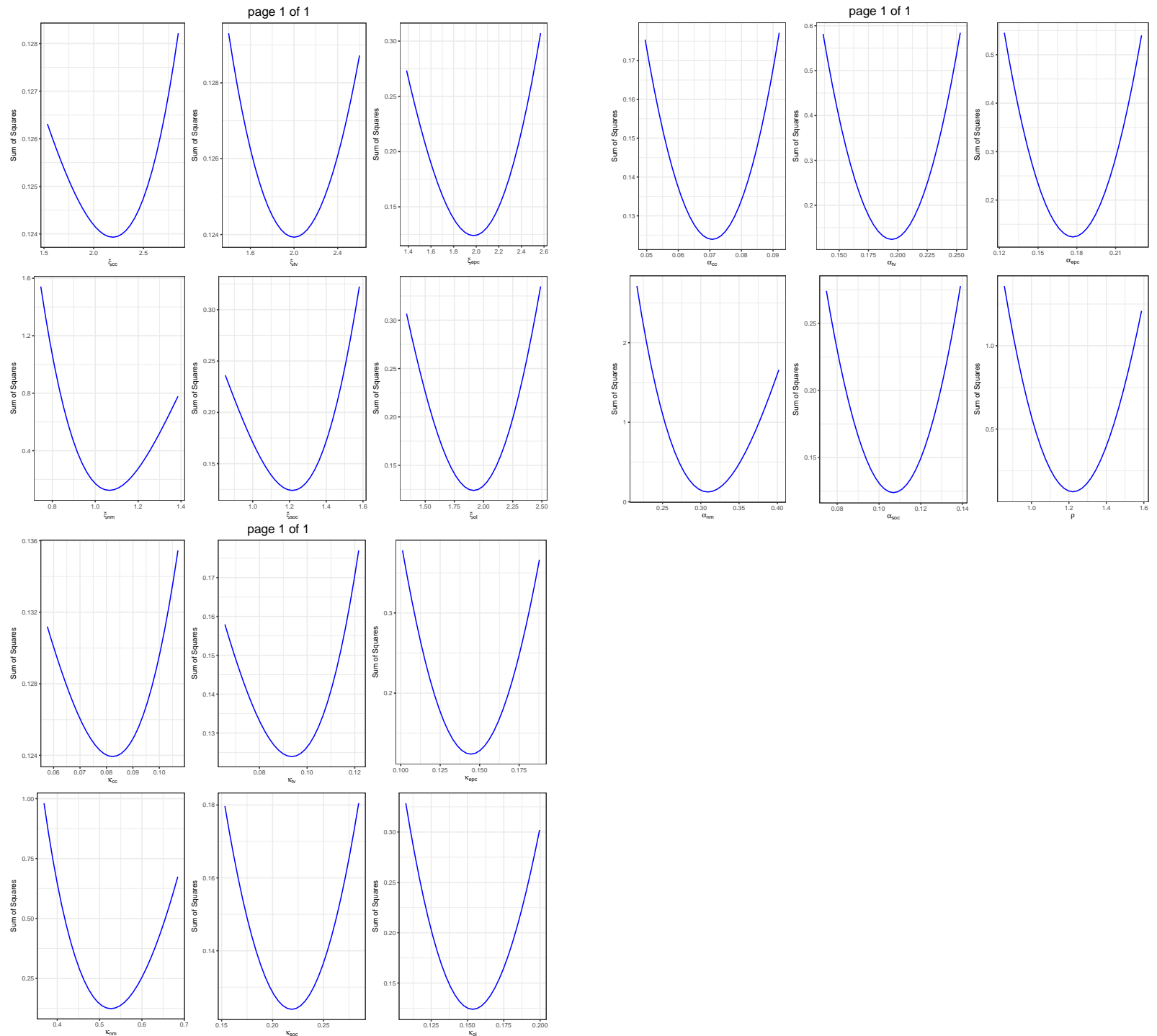

Notes: Each sub-plot depicts the value of the objective function when a given parameter value changes in a neighborhood of its estimated value. 


\title{
D Robustness: Estimation with Education-Specific Prices
}

\author{
Table D.5: Parameter Estimates
}

\begin{tabular}{ccccccc}
\hline \multicolumn{7}{c}{ A. Becker Model } \\
\hline & Child & Non-market & TV & Social & Eat \& Pcare & Hobbies \\
& 2.368 & 1.086 & 2.049 & 1.337 & 1.986 & 1.974 \\
& $(0.030)$ & $(0.019)$ & $(0.024)$ & $(0.013)$ & $(0.016)$ & $(0.016)$ \\
$\kappa$ & 0.108 & 0.525 & 0.122 & 0.208 & 0.183 & 0.189 \\
& $(0.001)$ & $(0.011)$ & $(0.000)$ & $(0.003)$ & $(0.001)$ & $(0.001)$ \\
$\alpha$ & 0.076 & 0.295 & 0.195 & 0.111 & 0.178 & 0.144 \\
& $(0.002)$ & $(0.005)$ & $(0.001)$ & $(0.001)$ & $(0.001)$ & $(0.001)$ \\
$\rho$ & 1.331 & & & & & \\
& $(0.025)$ & & & & & \\
\hline
\end{tabular}

\begin{tabular}{|c|c|c|c|c|c|c|}
\hline \multicolumn{7}{|c|}{ B. Standard Model } \\
\hline$\sigma^{\mathcal{S}}$ & $\begin{array}{c}1.252 \\
(0.017)\end{array}$ & & & & & \\
\hline$\phi^{s}$ & $\begin{array}{c}0.287 \\
(0.005)\end{array}$ & & & & & \\
\hline \multicolumn{7}{|c|}{ C. Multiple Goods Model } \\
\hline$\mu$ & $\begin{array}{c}0.006 \\
(0.000)\end{array}$ & $\begin{array}{c}0.747 \\
(0.007)\end{array}$ & $\begin{array}{c}0.013 \\
(0.001)\end{array}$ & $\begin{array}{c}0.063 \\
(0.001)\end{array}$ & $\begin{array}{c}0.085 \\
(0.002)\end{array}$ & $\begin{array}{c}0.087 \\
(0.002)\end{array}$ \\
\hline$\eta$ & $\begin{array}{c}0.706 \\
(0.011)\end{array}$ & & & & & \\
\hline$\sigma^{m}$ & $\begin{array}{c}1.247 \\
(0.016)\end{array}$ & & & & & \\
\hline$\phi^{m}$ & $\begin{array}{c}0.342 \\
(0.002) \\
\end{array}$ & & & & & \\
\hline \multicolumn{7}{|c|}{ D. Two Activity Model } \\
\hline & Home & Leisure & & & & \\
\hline$\xi$ & $\begin{array}{c}1.093 \\
(0.021)\end{array}$ & $\begin{array}{c}1.599 \\
(0.015)\end{array}$ & & & & \\
\hline$\kappa$ & $\begin{array}{c}0.476 \\
(0.011)\end{array}$ & $\begin{array}{c}0.171 \\
(0.001)\end{array}$ & & & & \\
\hline$\alpha$ & $\begin{array}{c}0.451 \\
(0.003)\end{array}$ & $\begin{array}{c}0.549 \\
(0.003)\end{array}$ & & & & \\
\hline$\rho$ & $\begin{array}{c}0.702 \\
(0.033)\end{array}$ & & & & & \\
\hline
\end{tabular}

Notes: The table reports the means of the bootstrapped distributions for the preference parameters of the four models considered. These are described in Sections 3.1, 3.2, 3.3 and 3.4, respectively. Bootstrapped standard errors are shown in parentheses. 
Table D.6: Dispersion in Hours Worked - Data vs. Models

\begin{tabular}{lcc}
\hline & Dispersion & $\begin{array}{c}\text { Dispersion } \\
\text { (as \% of data) }\end{array}$ \\
\hline Data & 0.439 & 1.000 \\
Becker & 0.230 & 0.523 \\
Standard & 0.125 & 0.285 \\
Multiple Goods & 0.122 & 0.278 \\
Two Activity & 0.140 & 0.337 \\
\hline
\end{tabular}

Notes: Estimation with education-specific prices.

Figure D.4: Response of Hours Worked to a Percentage Wage Change

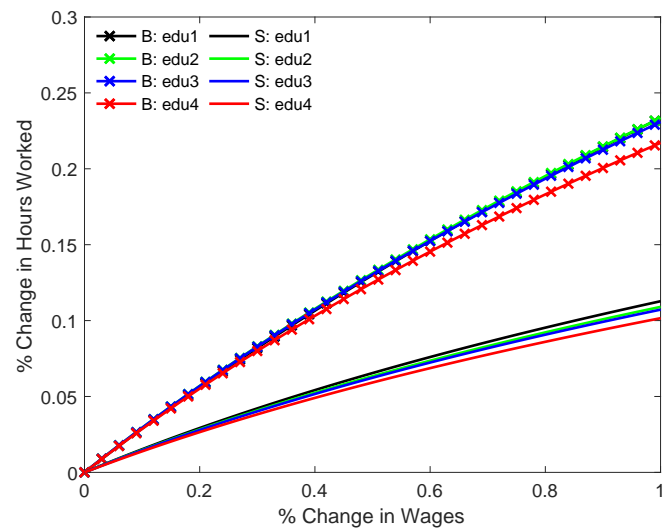

(a) Becker vs. Standard

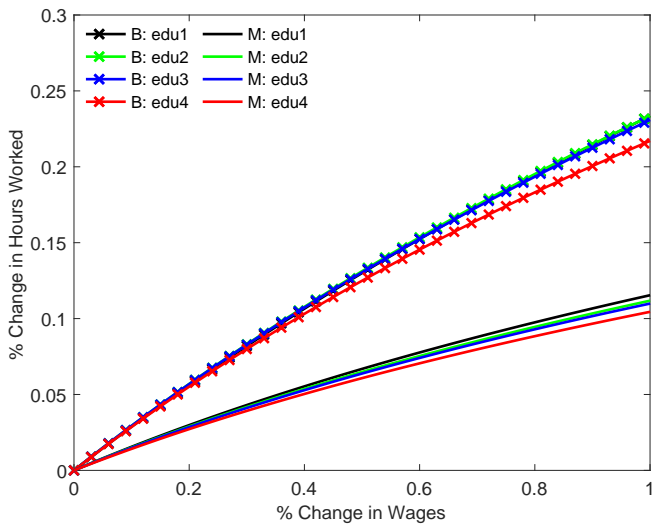

(b) Becker vs. Multiple-Goods

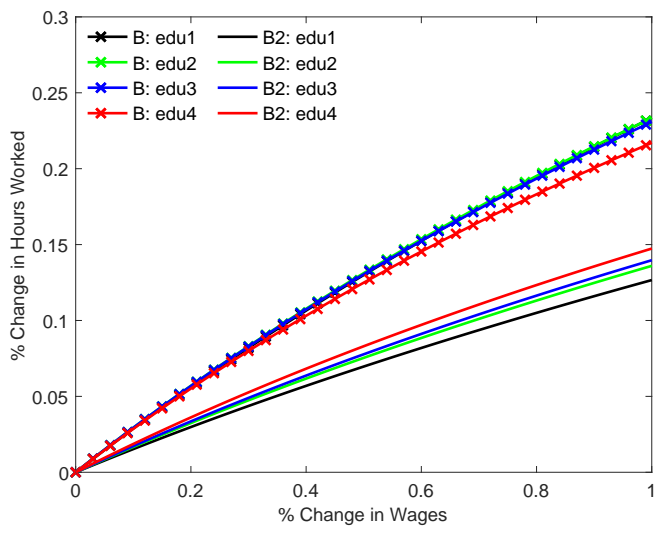

(c) Becker vs. Two Activity

Notes: 'B' refers to the Becker model, 'S' to the Standard model, ' $\mathrm{M}$ ' to the Multiple Goods model, and 'B2' to the Two Activity model. The four education categories are defined as follows: edu1 - less than high school, edu2 - high school, edu3 - some college, edu4 college and above. 


\section{E Model Solution}

\section{E.1 Becker Model}

Let $i$ be the index for an activity and $j$ be the index for education. For the ease of notation, define $C_{j}=\left(\sum_{i} \alpha_{i} c_{i j}^{\frac{\rho-1}{\rho}}\right)^{\frac{\rho}{\rho-1}}$. The utility function for education $j$ is then given by:

$$
U\left(C_{j}\right)=\log \left(C_{j}\right), \quad C_{j}=\left(\sum_{i} \alpha_{i} c_{i j}^{\frac{\rho-1}{\rho}}\right)^{\frac{\rho}{\rho-1}}, \quad c_{i j}=\left(\kappa_{i} x_{i j}^{\frac{\xi_{i}-1}{\xi_{i}}}+\left(1-\kappa_{i}\right)_{i j}^{\frac{\xi_{i}-1}{\xi_{i}}}\right)^{\frac{\xi_{i}}{\xi_{i}-1}} .
$$

The budget constraint is:

$$
\sum_{i} p_{i j} x_{i j}=w_{j}\left(1-\sum_{i} \ell_{i j}\right)
$$

Each education group maximizes utility subject to the budget constraint. Let $\lambda_{j}$ be the lagrangian multiplier. The F.O.Cs are as follows:

$$
\begin{aligned}
& \frac{\partial U}{\partial c_{i j}} \frac{\partial c_{i j}}{\partial x_{i j}}=\lambda_{j} p_{i j} \\
& \frac{\partial U}{\partial c_{i j}} \frac{\partial c_{i j}}{\partial \ell_{i j}}=\lambda_{j} w_{j}
\end{aligned}
$$

Taking the ratio between these two equations gives:

$$
\frac{\ell_{i j}}{x_{i j}}=\left(\frac{p_{i j}}{w_{j}}\right)^{\xi_{i}}\left(\frac{1-\kappa_{i}}{\kappa_{i}}\right)^{\xi_{i}}
$$

Simple manipulations of the definition of $c_{i j}$ gives:

$$
c_{i j}=x_{i j} \kappa_{i}^{\frac{\xi_{i}}{\xi_{i}-1}}\left(1+\frac{1-\kappa_{i}}{\kappa_{i}}\left(\frac{\ell_{i j}}{x_{i j}}\right)^{\frac{\xi_{i}-1}{\tilde{\xi}_{i}}}\right)^{\frac{\xi_{i}}{\xi_{i}-1}}
$$

Plugging equation (7) into the above equation gives:

$$
c_{i j}=x_{i j} \kappa_{i}^{\frac{\xi_{i}}{\xi_{i}-1}}\left(1+\left(\frac{1-\kappa_{i}}{\kappa_{i}}\right)^{\xi_{i}}\left(\frac{p_{i j}}{w_{j}}\right)^{\xi_{i}-1}\right)^{\frac{\xi_{i}}{\xi_{i}-1}}
$$

Define $M_{i j}=\kappa_{i}^{\frac{\xi_{i}}{\xi_{i}-1}}\left(1+\left(\frac{1-\kappa_{i}}{\kappa_{i}}\right)^{\xi_{i}}\left(\frac{p_{i j}}{w_{j}}\right)^{\xi_{i}-1}\right)^{\frac{\xi_{i}}{\xi_{i}-1}}$. We have $c_{i j}=M_{i j} x_{i j}$.

From equation (5), we can derive the following equation between activity $i$ and 
activity 1:

$$
\frac{\frac{\partial U}{\partial c_{1 j}} \frac{\partial c_{1 j}}{\partial x_{1 j}}}{\frac{\partial U}{\partial c_{i j}} \frac{\partial c_{i j}}{\partial x_{i j}}}=\frac{p_{1 j}}{p_{i j}}
$$

Plugging in the partial derivatives gives:

$$
\frac{\alpha_{1} c_{1 j}^{\frac{-1}{\rho}}\left(\frac{c_{1 j}}{x_{1 j}}\right)^{\frac{1}{\xi_{1}}} \kappa_{1}}{\alpha_{i} c_{i j}^{\frac{-1}{\rho}}\left(\frac{c_{i j}}{x_{i j}}\right)^{\frac{1}{\xi_{i}}} \kappa_{i}}=\frac{p_{1 j}}{p_{i j}} .
$$

Plugging $c_{i j}=M_{i j} x_{i j}$ into the above equation gives:

$$
\frac{x_{i j}}{x_{1 j}}=\left(\frac{p_{1 j}}{p_{i j}}\right)^{\rho}\left(\frac{\alpha_{i} \kappa_{i}}{\alpha_{1} \kappa_{1}}\right)^{\rho} \frac{M_{i j}^{\frac{\rho-\xi_{i}}{\xi_{i}}}}{M_{1 j}^{\frac{\rho-\xi_{1}}{\xi_{1}}}} .
$$

Define $N_{i 1 j}=\left(\frac{p_{1 j}}{p_{i j}}\right)^{\rho}\left(\frac{\alpha_{i} \kappa_{i}}{\alpha_{1} \kappa_{1}}\right)^{\rho} \frac{M_{i j}^{\frac{\rho-\xi_{i}}{\xi_{i}}}}{M_{1 j}^{\frac{\rho-\xi_{1}}{\xi_{1}}}}$. Then, $x_{i j}=N_{i 1 j} x_{1 j}$. This and equations (7) give $\ell_{i j}$ as a function of $x_{1 j}$ :

$$
\ell_{i j}=\left(\frac{p_{i j}}{w_{j}}\right)^{\xi_{i}}\left(\frac{1-\kappa_{i}}{\kappa_{i}}\right)^{\xi_{i}} N_{i 1 j} x_{1 j}
$$

The budget constraint can be rewritten as follows:

$$
\begin{gathered}
x_{1 j} \sum_{i} p_{i j} \frac{x_{i j}}{x_{1 j}}=w_{j}\left(1-\sum_{i} \ell_{i j}\right) . \\
x_{1 j} \sum_{i} p_{i j} N_{i 1 j}=w_{j}\left[1-\sum_{i}\left(\frac{p_{i j}}{w_{j}}\right)^{\xi_{i}}\left(\frac{1-\kappa_{i}}{\kappa_{i}}\right)^{\xi_{i}} N_{i 1 j} x_{1 j}\right] .
\end{gathered}
$$

Solve $x_{1 j}$ from the above equation gives:

$$
x_{1 j}=\frac{w_{j}}{\sum_{i} p_{i j} N_{i 1 j}+w_{j} \sum_{i}\left(\frac{p_{i j}}{w_{j}}\right)^{\xi_{i}}\left(\frac{1-\kappa_{i}}{\kappa_{i}}\right)^{\xi_{i}} N_{i 1 j}}
$$

$x_{i j}$ can then be solved from equation (12) and $\ell_{i j}$ can be solved from equation (7). 


\section{E.2 Standard Model}

Define $C_{j}^{S}=\left(\phi^{S}\left(x_{j}^{S}\right)^{\frac{\sigma^{S}-1}{\sigma^{S}}}+\left(1-\phi^{S}\right)\left(\ell_{j}^{S}\right)^{\frac{\sigma^{S}-1}{\sigma^{S}}}\right)^{\frac{\sigma^{S}}{\sigma^{S}-1}}$. The utility function for eduction $j$ is given by:

$$
U\left(C_{j}^{S}\right)=\log \left(C_{j}^{S}\right), \quad C_{j}^{S}=\left(\phi^{S}\left(x_{j}^{S}\right)^{\frac{\sigma^{S}-1}{\sigma^{S}}}+\left(1-\phi^{S}\right)\left(\ell_{j}^{S}\right)^{\frac{\sigma^{S}-1}{\sigma^{S}}}\right)^{\frac{\sigma^{S}}{\sigma^{S}-1}} .
$$

Normalize the price of $x_{j}^{s}$ to one. The budget constraint is

$$
x_{j}^{s}=w_{j}\left(1-\ell_{j}^{s}\right)
$$

Let $\lambda_{j}^{s}$ be the lagrange multiplier. The first order conditions are:

$$
\begin{aligned}
\left(C_{j}^{S}\right)^{\frac{1}{\sigma^{S}}} \phi^{S}\left(x_{j}^{S}\right)^{-\frac{1}{\sigma^{S}}} & =\lambda_{j}^{S} \\
\left(C_{j}^{S}\right)^{\frac{1}{\sigma^{S}}}\left(1-\phi^{S}\right)\left(\ell_{j}^{S}\right)^{-\frac{1}{\sigma^{S}}} & =\lambda_{j}^{S} w_{j} .
\end{aligned}
$$

The ratio between these two equations gives:

$$
\frac{\ell_{j}^{s}}{x_{j}^{s}}=\left(\frac{1}{w_{j}}\right)^{\sigma^{s}}\left(\frac{1-\phi^{s}}{\phi^{s}}\right)^{\sigma^{s}} .
$$

Plug equation (20) into the budget constraint gives:

$$
x_{j}^{s}=\frac{w_{j}}{1+\left(w_{j}\right)^{1-\sigma^{s}}\left(\frac{1-\phi^{s}}{\phi^{s}}\right)^{\sigma^{s}}} .
$$

\section{E.3 Multiple Goods Model}

Define $C_{j}^{m}=\left(\phi^{m}\left(X_{j}^{m}\right)^{\frac{\sigma^{m}-1}{\sigma^{m}}}+\left(1-\phi^{m}\right)\left(\ell_{j}^{m}\right)^{\frac{\sigma^{m}-1}{\sigma^{m}}}\right)^{\frac{\sigma^{m}}{\sigma^{m}-1}}$. The utility function for education $j$ is given by:

$$
\begin{gathered}
U\left(C_{j}^{m}\right)=\log \left(C_{j}^{m}\right), \quad C_{j}^{m}=\left(\phi^{m}\left(X_{j}^{m}\right)^{\frac{\sigma^{m}-1}{\sigma^{m}}}+\left(1-\phi^{m}\right)\left(\ell_{j}^{m}\right)^{\frac{\sigma^{m}-1}{\sigma^{m}}}\right)^{\frac{\sigma^{m}}{\sigma^{m}-1}} \\
X_{j}^{m}=\left(\sum_{i} \mu_{i}\left(x_{i j}^{m}\right)^{\frac{\eta-1}{\eta}}\right)^{\frac{\eta}{\eta-1}}
\end{gathered}
$$


The budget constraint is:

$$
\sum_{i} p_{i j} x_{i j}^{m}=w_{j}\left(1-\ell_{j}^{m}\right)
$$

Let $\lambda_{j}^{m}$ be the lagrange multiplier. The first order conditions are given by:

$$
\begin{aligned}
\frac{\partial U}{C_{j}^{m}} \frac{\partial C_{j}^{m}}{\partial X_{j}^{m}} \frac{\partial X_{j}^{m}}{\partial x_{i j}^{m}} & =\lambda_{j}^{m} p_{i j} \\
\frac{\partial U}{C_{j}^{m}} \frac{\partial C_{j}^{m}}{\partial \ell_{j}^{m}} & =\lambda_{j}^{m} w_{j} .
\end{aligned}
$$

Using (23) between activity $i$ and activity $1, \frac{x_{i j}^{m}}{x_{1 j}^{m}}$ can be derived as follows.

$$
\begin{aligned}
& \frac{\partial X_{j}^{m}}{\partial x_{1 j}^{m}} \frac{\mu_{1}\left(x_{1 j}^{m}\right)^{-\frac{1}{\eta}}}{\partial x_{i j}^{m}}=\frac{p_{1 j}}{\mu_{i}\left(x_{i j}^{m}\right)^{-\frac{1}{\eta}}}, \\
& \frac{x_{i j}^{m}}{x_{1 j}^{m}}=\left(\frac{p_{1 j}}{p_{i j}}\right)^{\eta}\left(\frac{\mu_{i}}{\mu_{1}}\right)^{\eta} .
\end{aligned}
$$

Plugging (26) into the expression for $X_{j}^{m}$ gives:

$$
X_{j}^{m}=\mu_{1}^{\frac{\eta}{\eta-1}}\left[\sum_{i}\left(\frac{\mu_{i}}{\mu_{1}}\right)^{\eta}\left(\frac{p_{1 j}}{p_{i j}}\right)^{\eta-1}\right]^{\frac{\eta}{\eta-1}} x_{1 j}^{m}
$$

Define $M_{j}^{m}=\mu_{1}^{\frac{\eta}{\eta-1}}\left[\sum_{i}\left(\frac{\mu_{i}}{\mu_{1}}\right)^{\eta}\left(\frac{p_{1 j}}{p_{i j}}\right)^{\eta-1}\right]^{\frac{\eta}{\eta-1}}$. Hence $X_{j}^{m}=M_{j}^{m} x_{1 j}^{m}$.

Taking ratio between (23) for activity 1 and (24) gives:

$$
\begin{aligned}
& \frac{\frac{\partial C_{j}^{m}}{\partial X_{j}^{m}} \frac{\partial X_{j}^{m}}{\partial x_{1 j}^{m}}}{\frac{\partial C_{j}^{m}}{\partial \ell_{j}^{m}}}=\frac{\phi^{m}\left(X_{j}^{m}\right)^{-\frac{1}{\sigma^{m}}} \mu_{1}\left(\frac{X_{j}^{m}}{x_{1 j}^{m}}\right)^{\frac{1}{\eta}}}{\left(1-\phi^{m}\right)\left(\ell_{j}^{m}\right)^{-\frac{1}{\sigma^{m}}}}=\frac{p_{1 j}}{w_{j}}, \\
& \ell_{j}^{m}=\left(\frac{p_{1 j}}{w_{j}}\right)^{\sigma^{m}}\left(\frac{1-\phi^{m}}{\phi^{m} \mu_{1}}\right)^{\sigma^{m}}\left(M_{j}^{m}\right)^{\frac{\eta-\sigma^{m}}{\eta}} x_{1 j}^{m} .
\end{aligned}
$$

Plugging (26) and (29) into the budget constraint gives:

$$
x_{1 j}^{m}=\frac{w_{j}}{w_{j}\left(\frac{p_{1 j}}{w_{j}}\right)^{\sigma^{m}}\left(\frac{1-\phi^{m}}{\phi^{m} \mu_{1}}\right)^{\sigma^{m}}\left(M_{j}^{m}\right)^{\frac{\eta-\sigma^{m}}{\eta}}+\sum_{i} p_{i j}\left(\frac{p_{1 j}}{p_{i j}}\right)^{\eta}\left(\frac{\mu_{i}}{\mu_{1}}\right)^{\eta}} .
$$


$x_{i j}^{m}$ can then be solved from equation (26) and $\ell_{j}^{m}$ can be solved from equation (29). 